Word \# 8678

\title{
Key characteristics of academics promoting Sustainable Human Development within engineering studies
}

\author{
${ }^{1}$ Boris Lazzarini, ${ }^{2}$ Agustí Pérez-Foguet, ${ }^{3}$ Alejandra Boni \\ ${ }^{1}$ Universitat Politècnica de Catalunya- BarcelonaTech, Research Institute of Sustainability Science \\ and Technology, Engineering Sciences and Global Development (EScGD) Research Group, c/ Jordi \\ Girona 31, Ed. TG - S1, 08034 Barcelona, Spain, boris.lazzarini@upc.edu \\ ${ }^{2}$ Universitat Politècnica de Catalunya - BarcelonaTech, School of Civil Engineering, Department of \\ Civil and Environmental Engineering, Research Institute of Sustainability Science and Technology, \\ Engineering Sciences and Global Development (EScGD) Research Group, c/ Jordi Girona 1-3, C2 \\ 310, 08034 Barcelona, Spain, agusti.perez@upc.edu \\ ${ }^{3}$ Universitat Politècnica de València, INGENIO (CSIC-UPV), Ed. 8E; Camino Vera s/n 46022, \\ Valencia, Spain, aboni@dpi.upv.es
}

Keywords: Engineering, Sustainable Development, Academic staff engagement, Sustainable Development Goals, Higher Education Policy.

\begin{abstract}
In the last decade, a growing number of technical universities and engineering faculties have been promoting various initiatives aimed at integrating sustainable development in their activities. Despite the fact that the commitment of the academic staff has been widely recognised to have a key role in university change processes towards sustainable development, few studies have specifically analysed the characteristics of academics engaged in such processes. The present study provides an analysis and a profile of a group of academics, participating in a training programme on sustainable human development, granted by a European fund. The methods employed include a semi-structured survey, focussing on the academic activities and social outreach of the participants, complemented by a bibliometric analysis of their scientific production. The findings show: 1) an interdisciplinary profile of the academics, 2) an integration of sustainable development principles in all academic activities and 3) a promotion of those principles outside the university. It is emphasised that the commitment of this type of academics can facilitate a cultural change in engineering education, as well as more holistic transformations of universities towards sustainable development. The paper concludes by providing recommendations for leaders and policy makers of higher education institutions on the implementation of appropriate policies and mechanisms to facilitate faculty engagement in sustainable development.
\end{abstract}




\section{Highlights:}

- Engineering academics engaged SD are 'connectors' within and beyond university boundaries.

- Engineering academics engaged in SD conduct interdisciplinary research activities.

- HEI should explore appropriate policies and mechanisms to engage academics in SD. 


\section{Introduction}

Over the past few decades we have witnessed an increased political will in relation to Sustainable Development (SD), which has been identified as one of the greatest challenges that our societies are facing. This process of growing social recognition has guided the UN Millennium Project (UN Millennium Project, 2005) and the Post-2015 Development Agenda, leading to the final adoption of the Sustainable Development Goals (SDG) (United Nations, 2015).

Societal awareness of global challenges has increased tremendously in the last decade. This reflects wider societal debates that particularly concern higher education. The United Nations Decade of Education for Sustainable Development (DESD) 2005-2014 promoted the integration of the principles of Education for Sustainable Development (ESD) across all levels and aspects of education, with the goal of fostering a more sustainable society. Among the major achievements of the DESD we can highlight: i) a general reorientation of a number of education programmes, addressing and integrating sustainability issues at different levels; ii) an increasing convergence between sustainable development agendas and education agendas; and iii) the increase of important pedagogical innovations. Nonetheless, the final report indicates that more efforts are needed to further transform learning and training environments, especially by building the capacity of educators and trainers to properly integrate SD into their academic functions (UNESCO, 2014).

In response to this growing call, an increasing number of higher education institutions (HEI) have been engaged in incorporating SD into their systems (Lozano et al., 2015), reconsidering university policies (Wals, 2014), and the content of their curricula (Lozano and Lozano, 2014; von Blottnitz et al., 2015). Nevertheless, SD is not yet comprehensively integrated into higher education systems (Mulder et al., 2015) and the pace of change has been little and slow (Watson et al., 2013). Scientists and scholars have analysed and discussed the multiple barriers that hinder the consolidation of SD into higher education (Ferrer-Balas et al., 2008; Lozano, 2006; Velazquez et al., 2006). In a more recent study, Verhulst and Lambrechts (2014) associate these barriers with different factors, such as: i) the lack of awareness or interest academics, students and staff have concerning SD issues; ii) the structure of higher education, characterised to be conservative and disciplinary with strong resistance to change in the functions of education and research; and iii) the lack of resources and adequate institutional support.

Despite there being many examples of SD implementation throughout the higher education system, those efforts made in universities are generally compartmentalised (Lozano et al., 2015). Contextually, scientific literature highlights that the role of academic staff engaged in sustainability practices in the different functions of universities is essential in order to promote transformation at university level (Krizek et al., 2012; Lozano, 2006) and to better connect with the wider society (Ferrer-Balas et al., 2008). These academics, often heralded as 'sustainability champions' (Lozano, 2006) are generally not sufficiently supported nor incentivised by academic institutions (Hoover and Harder, 2014). For these reasons, reconsidering the role of academics engaged with SD as agents of change within university institutions and as interfacial connectors between universities and societal organisations is of primary importance to enhance university transformation (Hugé et al., 2018). Limited research is available on the research and academic profiles of academics integrating SD into their practice. 
Bearing this context in mind, this article aims to provide evidence to answer the question: are there any common patterns in the academic profile of academics engaged in SD practices? The research is designed to answer this question through a mixed approach. On the one hand, through a semi-structured survey aimed at analysing academic aspects such as: teaching innovation, the relation between teaching and research, the integration of SDGs in teaching and research, social outreach and collaboration, etc. On the other hand, through a bibliometric analysis - to expand the research profile of academics engaged in sustainability.

To accomplish this task, data have been collected by distributing the survey to a group of academics involved, at different levels, in the training activities promoted in the framework of the European initiative "Global Dimension in Engineering Education", a collaborative project promoted by a consortium of technical universities and Non-Governmental Organisations (NGO), aimed at improving the competences of academics in Sustainable Human Development (SHD). The bibliometric analysis was carried out by using maps of science, and focused on the academics that answered the survey.

The rest of the paper is structured as follows. The second section contains scientific literature on academic staff engagement, specifically focusing on technical universities. The third section describes the GDEE initiative. The fourth section introduces the research methods. The fifth section describes the empirical results. The sixth section contains the discussion of the findings. Finally, the seventh section presents our conclusions and proposes recommendations.

\section{Academic staff engagement in technical universities}

Technical faculties and universities are particularly susceptible to barriers to change concerning SD. The main reason is that engineering education is primarily focused on technical aspects and, traditionally, there have not been many opportunities to develop broader knowledge and skills to respond to the complexity of global problems related to SD, as reported by Crofton (2000). Despite the calls for a reform of engineering curricula to integrate SD (Watson et al., 2013), and the need to restructure teaching approaches (Leal Filho and Nesbit, 2016), engineering methods and tools are still characterised by a strong practical orientation and mostly focus on finding and implementing solutions that work with certainty and predictability (Halbe et al., 2015). Responses to calls for curricula reform in engineering are, in general, relatively limited (Fenner et al., 2005; Lozano and Lozano, 2014; von Blottnitz et al., 2015). It is worth highlighting specific approaches and strategies aimed at integrating SD principles into technical universities (Egelund Holgaard et al., 2016; Lozano et al., 2015; Rose et al., 2015). In addition, complementary perspectives have focused on promoting the convergence between engineering and development studies (Boni and PérezFoguet, 2008; Pérez-Foguet et al., 2005), following the theoretical framework of Sustainable Human Development (SHD) (Absell, 2015). However, significant updates of engineering curricula seem to be relatively limited (Davidson et al., 2010), and much of the strategies adopted by technical universities have primarily focused on developing individual courses on SD (von Blottnitz et al., 2015).

Various recommendations addressing academics have been proposed to trigger cultural change in an environment characterised by dominant structures based on technical paradigms and strong disciplinarity (Egelund Holgaard et al., 2016; Mulder et al., 2012; 
Sammalisto et al., 2015). Lozano (2006) recommends "detecting, engaging and empowering the individuals who are already convinced with the idea, making them SD champions to help them achieve a multiplier effect throughout the entire organisation". Nonetheless, it is widely recognised that $\mathrm{HEI}$ often do not provide adequate institutional support and incentives for those academics willing to integrate SD into their teaching and research activities (Hoover and Harder, 2014), and the majority of endeavours are primarily made for the personal satisfaction of overcommitted academics, and most go unrewarded (Krizek et al. 2012). In the case of engineering, activities not falling within the disciplinary context of the core technical content are often not fully recognised during the evaluation of teaching and research merits. The literature analysing the education of engineers for SD and its relevant challenges, emphasises the need for complementary approaches to foster changes in engineering curricula (Krogh Hansen et al., 2014; Mulder et al., 2012). Specifically, the scholars point out that top-down institutional support has to be complemented with bottom up initiatives, aimed at further engaging motivated academics. It is vital, thus, to effectively tackle this shortcoming, identifying the drivers to foster the empowerment and the active engagement of academics in sustainability education and research.

Ferrer-Balas et al. (2008), in a work comparing sustainability transformation across seven scientific-based and technical universities worldwide, discuss barriers as well as internal and external drivers of university transformation towards SD. The research conclusions point out that, on the one hand, among the various factors that affect transformation towards SD, the main barrier to overcome is "the lack of an incentive structure for promoting changes at the individual level". On the other hand, the authors highlight the main driver affecting transformation as the existence of "connectors" with society. Specifically, connectors are identified with networks of people engaging in interactions between departments or with nonacademic societal entities. These connectors can be interdisciplinary research groups as well as professors or groups engaged with societal challenges. Language, practices, approaches and incentives adopted by connectors can influence diverse actors of universities, encouraging the creation of a critical mass of professionals engaged with SD (Ferrer-Balas et al., 2010).

Recent literature reinforces these findings. The promotion of change at the individual level as a starting point to bring about greater change has been emphasised in current research (Barth and Rieckmann, 2012; Cebrián et al., 2015; Hoover and Harder, 2014). However, support and appropriate incentive structures aimed at maximising academic engagement are still lacking (Krizek et al., 2012; Wood et al., 2016). Furthermore, which kind of incentive structures should be offered to academics appears to be still largely undefined, with a risk of oversimplification (such as the increase of research funding, fostering career perspective, etc.). In fact, the literature highlights that the perceived role of academics involved in SD has been changing, above all over the last decade, due to increasing and contradictory pressures of the globalisation of higher education and the competition between universities in global networks (White, 2015). The increased relevance of rankings, benchmarking and the focus on scientific and economic productivity of $\mathrm{HEI}$, has turned academics, according to Morrissey (2013), into "economic units of use" where managing tasks and achieving 'business' targets have exceeded traditional goals, such as excellent teaching. Contextually, recent research highlights different "academic identities" among sustainability champions committed to embedding sustainability in curricula and pedagogy (Wood et al., 2016). Accordingly, engaged academics give meaning to their role as educators in their efforts towards the integration of sustainability in their teaching approaches, through personal motivation and 
different narratives that emphasise a diverse and personal way to engage with and practice SD (ibid.). Therefore, further research is needed to define incentives and institutional approaches to maximise the long-term organisational impact of SD champions.

The existence of 'connectors' with other research groups inside universities and with society at large is undoubtedly an essential driver to promote transformation towards SD. In this sense, it is widely accepted that to address sustainability challenges - namely, complex multi-stakeholder problems of high social and environmental relevance - it is necessary to have approaches that transcend the boundaries of disciplines and the boundaries of universities themselves, including diverse perspectives and knowledge of non-scientific stakeholders in research processes (Gaziulusoy and Boyle, 2013; Lang et al., 2012; Wals, 2014). Nonetheless, the overspecialisation of research and the fragmentation of knowledge through disciplinary boundaries are still common in engineering faculties (Halbe et al., 2015), and 'connection' - within university borders and with society as a whole - should be enhanced in order to overcome this shortcoming. In fact, there is a claim of more permanent relations between universities and external non-academic partners (Mulder et al., 2012; Velazquez et al., 2006), and to foster the collaboration with international networks to accelerate SD learning and transformation (Withycombe Keeler et al., 2016).

\section{The GDEE initiative}

The GDEE initiative is a European network whose aim is to increase the awareness, critical understanding and attitudinal values of undergraduates and postgraduate students in technical universities across Europe in connection with SHD and its relationship with technology. This objective was tackled by integrating SHD as a cross-cutting issue in teaching activities, improving the competences of academics, and through engaging both staff and students in initiatives related to SHD. It started in 2012 as a collaborative project between a consortium of European Universities and NGOs in Spain, Italy and the United Kingdom funded by EuropeAid, and was completed at the end of 2015.

The pedagogical approach, based on the previous works of project partners (Boni and Pérez-Foguet, 2008; Pérez-Foguet et al., 2005), has been extensively described elsewhere (Pérez-Foguet et al., 2018; Trimingham et al., 2016). For the purpose of this research, it is worth mentioning that the project strategy was based on a continuous professional development approach addressing academics focused on three main areas: competences, connectivity and collaboration.

1. Competences: enhancing the competences of academics and students with regard to their understanding of SHD issues and their capability to mainstream them in the academic curricula;

2. Connectivity: enhancing the capability of academic institutions to connect and share efforts within and across EU Member States as well as share and disseminate results and best practices regarding the integration of MDGs/SDGs into technology studies;

3. Collaboration: enhancing the ability to work with other stakeholders, notably NonGovernmental Organisations (NGOs) in order to advance a more practical dimension to the work carried out at academic levels.

Through activities related to each one of these three areas the project has been promoted by emphasising the integration of a Global Dimension (GD) of engineering education. The focus 
on the GD encourages students to think of themselves as global citizens and thus promote a sense of global social responsibility. This specific approximation on the incorporation of SD into academic activities, expressly promotes an understanding of different issues related to global development: extreme poverty, human rights, globalisation, equality issues and environmental challenges. This emphasis on the global impact of engineering activities worldwide integrates other agendas related to development contexts, such as: sustainable development, humanitarian engineering and ethics. However, the benefits of including a GD is that it can help students make links with the complexities of the real world, and enable them to think of themselves as actors able to play an active role in poverty reduction, human rights issues, and conflict resolution. The composition of the consortium, comprising universities and NGOs, reflects the approach promoted with this initiative: fostering the cooperation between NGOs and academia as key factors in reinforcing the presence of SHD in formal teaching programmes at all levels of engineering education (Zolezzi et al., 2013).

According to this strategy, the project included different complementary activities aimed at up-skilling, motivating and engaging academics with development issues, as well as promoting sustainability issues in engineering education. Among the main project outcomes, nine online courses were developed in order to increase the competences and abilities of academic staff of technical or science-based universities to integrate development-related issues into their teaching and research activities. For the implementation of each course, a set of training materials was developed by selected European experts in this field (GDEE, 2014), as well as a set of teaching resources aimed at supporting lecturers at integrating sustainability issues in teaching activities (GDEE, 2015). All these resources are available online at the project website (http://gdee.eu/) distributed as Open Educational Resources.

At the time of the completion of the project, in April 2015, the GDEE community comprised of almost five hundred members from a total of eighty-four different universities. The network includes different profiles, mostly academics but also non-academic experts in the field of development (from NGOs, development training centres, and engineering organisations). Some of them were directly involved in the activities of the project; others are participants who attended online GDEE courses offered in the three partner countries; and a further group are academics or professionals interested in joining the activities of the network. With respect to this research, it is worth mentioning that almost one hundred professionals, mostly academics, have closely collaborated in developing training and teaching materials as well as in the delivery, coordination and evaluation of online courses. On the other hand, more than two hundred people, mostly academics, enrolled in one or more online courses, with a total of 885 enrolments.

\section{Methods}

Starting from the context described earlier, this research aims to analyse and characterise a group of academics of the GDEE community, in order to enhance the understanding of the academic profile of academics engaged in SD issues in order to:

- identify the characteristics and common patterns of this community;

- foster the replicability of the initiative in different contexts.

The group comprises 90 academics with different degrees of expertise and involvement in SD practices, but who are all engaged and interested in integrating sustainability. On the one hand, 43 contributors who are experts in SHD, who closely collaborated in the development 
of training materials as well as in the delivery of online courses. On the other hand, 47 participants who are academics from engineering or science-based Spanish universities, who completed one or more courses offered through the Spanish virtual platform.

Methods included: i) an analysis of a semi-structured survey aimed at deepening the understanding of the academic profile of academics involved in activities related with SD; and ii) a bibliometric analysis of the scientific publications of those academics that have completed the survey in order to expand their scientific profile.

\subsection{Semi-structured survey}

A survey aimed at broadening the understanding of the academic profile of academics engaged in GDEE activities was carried out.

Following the work of Larrán-Jorge et al. (2015), as a reference point for the design and validation process of the questionnaire, the data collection tool was designed and validated through different steps. First of all, an extensive literature review was performed to design the survey. Various fields were explored prior to identifying a list of potential items to be included in the survey, such as: teaching innovation (Segalàs et al., 2010, 2009; Wiek et al., 2011), outreach (Lozano-García et al., 2006), SD research (Clark and Dickson, 2003; Kajikawa et al., 2007), academic satisfaction towards accreditation (Byrne et al., 2013; Caballero Rodríguez, 2013). Then, based on Foxcroft's methods (Foxcroft et al., 2004), two survey validations were conducted: the first involving a group of researchers belonging to the GDEE Spanish universities partners; and the second involving a group of academics of the Institute of Sustainability Science and Technology of the Polytechnic University of Catalonia.

The survey was divided into six categories:

1. Academic profile of the respondents (affiliation, accredited years of teaching and research)

2. Teaching activities: including specific information on subjects taught by respondents (such as student evaluation and grading criteria) and engagement of respondents in teaching innovation activities.

3. Research activities: including the main research fields of respondents, especially focusing on the relation between research and teaching activities.

4. Degree of integration of SDGs in the teaching and research activities of respondents, as well as the perceived relation between crosscutting competences adopted by HEI and SDGs.

5. Social outreach and collaboration: entities with which respondents regularly cooperate and the type of collaboration.

6. Perception of the recognition/evaluation of academics merits including university evaluation and regional/national accreditation agencies.

The survey was comprised of 23 closed-ended questions, mostly employing a 5 point Likert scale from 'totally disagree' to 'totally agree', as well as ranking and multiple-choice questions, which were complemented with 13 open-ended questions to ask respondents for broader information based on their experience on various academic issues. Table 1 shows the survey structure in detail. 
Table 1. Survey structure

\begin{tabular}{|l|l|}
\hline \multicolumn{2}{|c|}{ Academic profile of the respondents } \\
\hline Professional data & Open-ended questions \\
\hline \multicolumn{2}{|c|}{ Teaching activities } \\
\hline Subjects taught & Open-ended questions \\
\hline Evaluation and grading criteria & Open-ended questions \\
\hline Engagement in teaching innovation activities & $\begin{array}{l}\text { Likert scale; Open-ended } \\
\text { questions }\end{array}$ \\
\hline \multicolumn{2}{|c|}{ Sustainable Development Goals } \\
\hline UNESCO nomenclature for fields of science and technology & Open-ended questions \\
\hline Relation between research and teaching & Likert scale \\
\hline \multicolumn{2}{|c|}{ Social outreach and collaboration } \\
\hline Degree of integration of SDGs in teaching and research & Likert scale \\
\hline $\begin{array}{l}\text { Relation between SDGs and university transversal } \\
\text { competences }\end{array}$ & Likert scale; Multiple-choice \\
\hline \multicolumn{2}{|c|}{ Perception of the recognition/evaluation of academic merits } \\
\hline Collaboration with social entities & Ranking \\
\hline Research dissemination channels & Multiple-choice \\
\hline \multicolumn{2}{|c|}{ Len-ended } \\
\hline University monitoring of academic activities & $\begin{array}{l}\text { Likert scale; Open-endions } \\
\text { questions }\end{array}$ \\
\hline Recognition of academic merits and promotion procedures
\end{tabular}

The aim of the survey was not to assess the engagement of academics in each specific SDG, but rather to identify the degree of integration of SDGs concept in the respondents' teaching and research activities, specifically those related to engineering. For this reason, SDGs were grouped into twelve items, described in Table 2.

Table 2. Sustainable Development Goals grouping

\begin{tabular}{|l|l|}
\hline \multicolumn{1}{|c|}{ Description } & \multicolumn{1}{c|}{ SDG } \\
\hline End of poverty and hunger & (SDGs 1, 2) \\
\hline Ensure healthy lives and well-being & (SDG 3) \\
\hline Inclusive, equitable and quality education & (SDG 4) \\
\hline Reduce inequalities and achieve gender equality & (SDGs 5, 10) \\
\hline Clean water and sanitation & (SDG 6) \\
\hline Affordable and clean energy & (SDG 7) \\
\hline Promotion of decent work and sustainable industrialisation & (SDGs 8, 9) \\
\hline $\begin{array}{l}\text { Sustainable cities/communities and sustainable production } \\
\text { and consumption patterns }\end{array}$ & (SDGs 11, 12) \\
\hline Climate change adaptation & (SDGs 13) \\
\hline Conservation and sustainable use of ecosystems & (SDGs 14, 15) \\
\hline Promotion of peace, justice and strong institutions & (SDG 16) \\
\hline Promotion of global partnership for SD & (SDG 17) \\
\hline
\end{tabular}


Due to the characteristics of the survey, and the need to integrate it with a bibliometric analysis, the authors decided to send it only to those members of the two groups analysed who had an active research profile. Consequently, as a preliminary step, it was decided to perform an 'author search', using the Scopus database, for each member of the groups, for a total of 90 authors, by entering the authors' last name, first name and affiliation. Findings showed that, roughly, $65 \%$ of the members of the community had a Scopus ID. The reasons for this are diverse. The group of contributors comprised of a number of NGO practitioners and other experts that do not have international research publications, whilst course participants included a number of professors without a Scopus ID, along with PhD students.

Finally, the survey was sent to 56 academics using the survey tool SoGoSurvey, and made available for a period of three months.

\subsection{Bibliometric analysis}

In conjunction with the survey, a bibliometric analysis was performed, aimed at deepening the research profile of the academics completing the survey.

This analysis included the following steps:

- The selection and analysis of the research publications of the GDEE community registered in the Scopus database.

- The generation of an overlaid journal map based on data downloaded from Scopus.

- The operationalisation of a disciplinary diversity index.

A comparison of the two scientific databases - Scopus and Web of Science (WoS) - was conducted, taking insights from the analysis made by Chadegani et al. (2013). Finally, Scopus was selected as our principal data resource due to its better adaptability to the characteristics of the GDEE community. In fact, the interest of the research was to identify and analyse the highest number of publications of the group of academics and Scopus has a broader coverage of journals, although they may be of lower impact.

The bibliometric analysis was only performed for those academics that completed the survey, following the methodological proposal of a recently published study on research profiling of academics engaged in SD (Lazzarini and Pérez-Foguet, 2018).

Traditional bibliometric analysis can be greatly enriched with the help of appropriate visualisations. Science maps, for example, are suitable tools for this purpose. They are visual representations built on the overall science interrelationship based on journal articles (Leydesdorff et al., 2015; Porter and Rafols, 2009), and help to visually identify major areas of science, their size, similarity and interconnectedness. Specifically, the use of science maps is particularly helpful since they enable the analysis different aspects of disciplinarity such as: i) the variety of "disciplines"; ii) the balance, or distribution, of disciplines (expressed by the relative size of nodes in the map); and iii) the disparity, or degree of difference, between the disciplines (expressed by the distance between the nodes of the map) (Porter and Rafols, 2009).

Given the purposes of this study, we opted for a base map tool called 'Overlay for data from Scopus' (Leydesdorff et al., 2015), namely a global map of science that can be interactively overlaid with journal distributions in sets downloaded from Scopus. Base maps can be used as a basic framework on which the journal distribution of a set of documents downloaded 
from Scopus can be projected. Subsequently, it is possible to assess the portfolio of documents in terms of the spread across journals and journal categories.

Furthermore, base maps can be used as distance maps for measuring interdisciplinarity in terms of journal composition (Leydesdorff et al., 2015). Simple and more complex indicators have been developed for the purpose of assessing interdisciplinarity of researchers (Porter et al., 2007). For the purpose of this research we opted to use the Rao-Stirling index. Unlike other diversity indexes commonly used to assess interdisciplinarity, such as Shannon or Herfindal indexes (Leydesdorff and Rafols, 2011), Rao-Stirling accounts not only for the variety, namely the number of disciplines of the publications analysed, but also for the disparity, namely the ecological distance among different subsets of journals (Porter and Rafols, 2009).

\section{Results and discussion}

\subsection{Analysis of the survey}

The survey was answered by 18 respondents from $7 \mathrm{HEI}$, representing a 33\% response rate of all the academics contacted. Even with the limitations related to the reduced number of respondents, the survey highlights important issues related to academic activity that complements the information provided by the bibliometric analysis.

\subsubsection{Profile of the survey respondents}

The respondents were mainly affiliated with Spanish polytechnic universities, with 7 respondents from the Polytechnic University of Catalunya, 4 from the Technical University of Madrid and 3 from the Technical University of Valencia. A further 3 respondents were from the Engineering faculties of different Spanish universities: Castilla-La Mancha, Rovira i Virgili and Alcalá. Additionally, an academic from the faculty of Architecture of the Universidade do Porto (Portugal), who completed GDEE courses through the Spanish learning platform, also answered the survey.

Figure 1 presents the faculty affiliation of the respondents. The faculty of Industrial Engineering was the most heavily represented, accounting for 35\%, followed by Civil Engineering (29\%) and Telecommunication Engineering (12\%). Other university faculties indicated were Agronomic Engineering, Architecture, Chemical Engineering and Environmental Sciences. Department affiliation followed roughly the same distribution. 


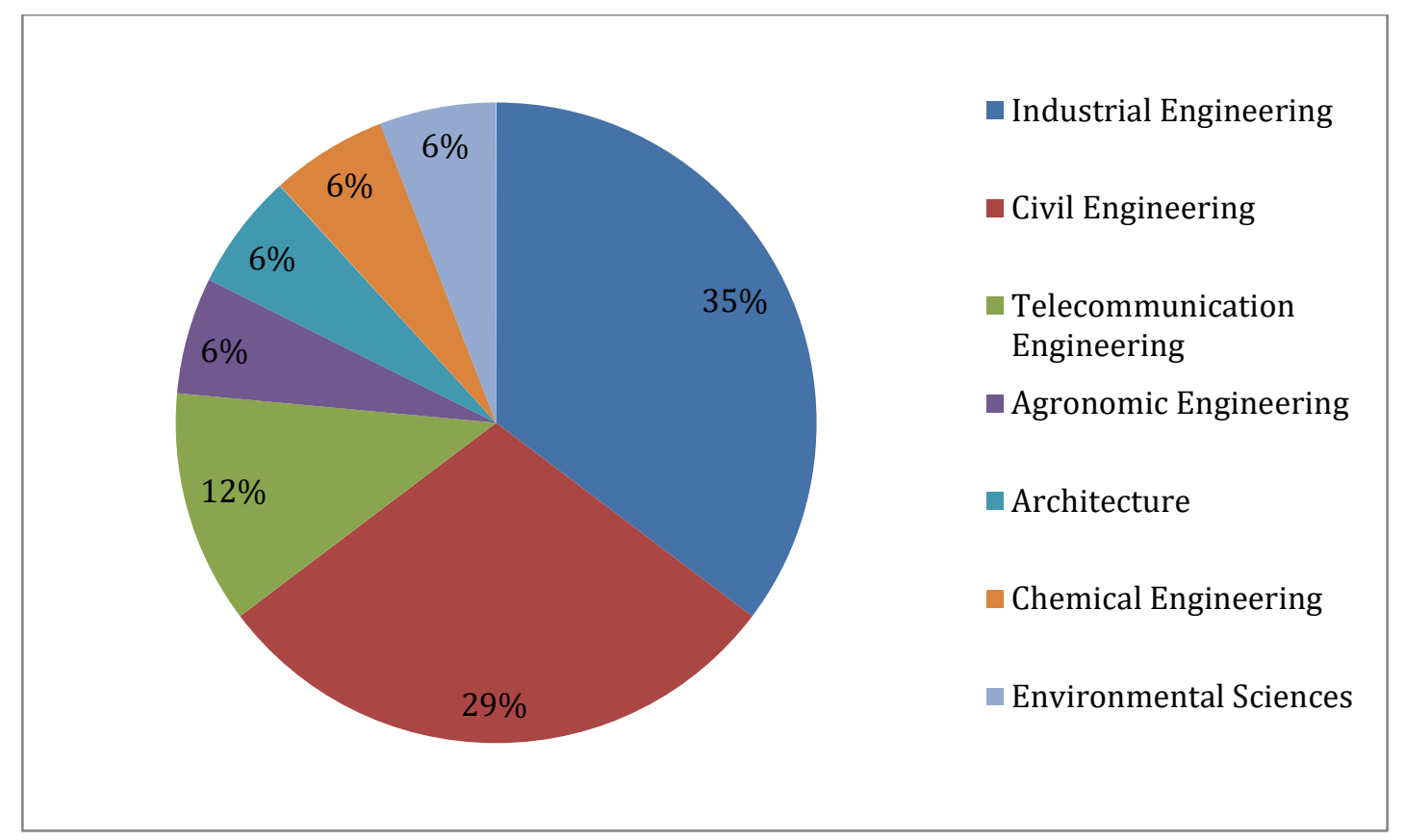

Figure 1. Faculty affiliation

The majority of the respondents were doctors (83\%), and females appeared to be more motivated to answer the survey (56\%). A total of $56 \%$ of the respondents were aged between 40-49 years. The group of respondents comprised both junior and senior researchers. Figure 2 shows the distribution of the years of professional teaching and research accredited by quality agencies.

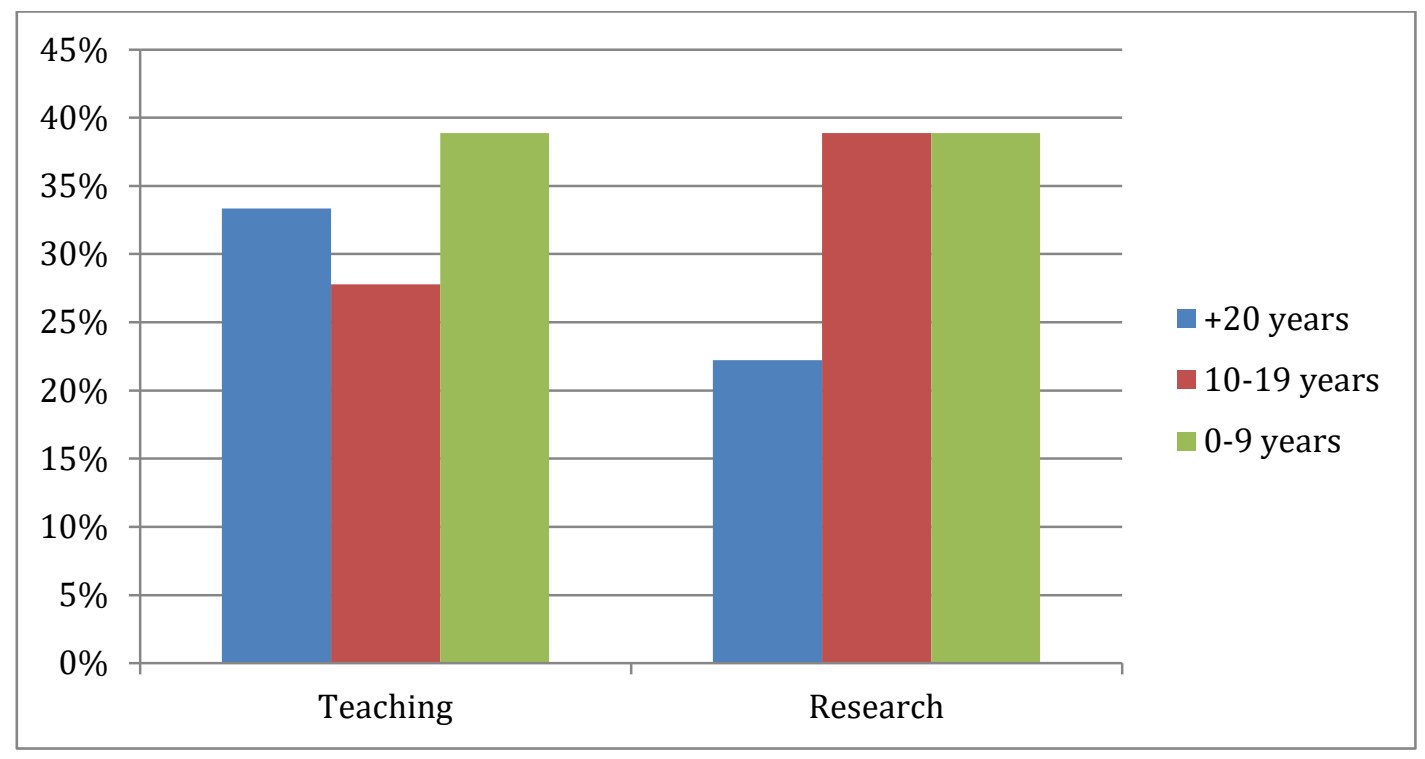

Figure 2. Distribution of accredited years of teaching and research

\subsubsection{Teaching activities}

The respondents were asked to indicate 1 to 3 subjects they taught, with reference to the last 5 years of their academic activity. Subsequently, they were asked to provide further information on specific issues, namely: i) the integration of mechanisms for the active 
participation of students; ii) the evaluation and grading criteria employed to evaluate students. In total 28 subjects were indicated by respondents, 16 subjects of bachelor's degrees and 12 of master's degrees. Additionally, respondents were asked to provide information on their engagement in activities of teaching innovation.

The great majority (85\%) of the subjects indicated by respondents had mechanisms for the active participation of students. Among the examples provided, shown in Figure 3, teamwork activities were, by far, the most important mechanism indicated, followed by online forums (offered via virtual platforms or social networks), then case study preparation and debates. It is worth mentioning a specific case highlighting teamwork activities in fieldwork, in the framework of a subject partially developed on-field, in Morocco.

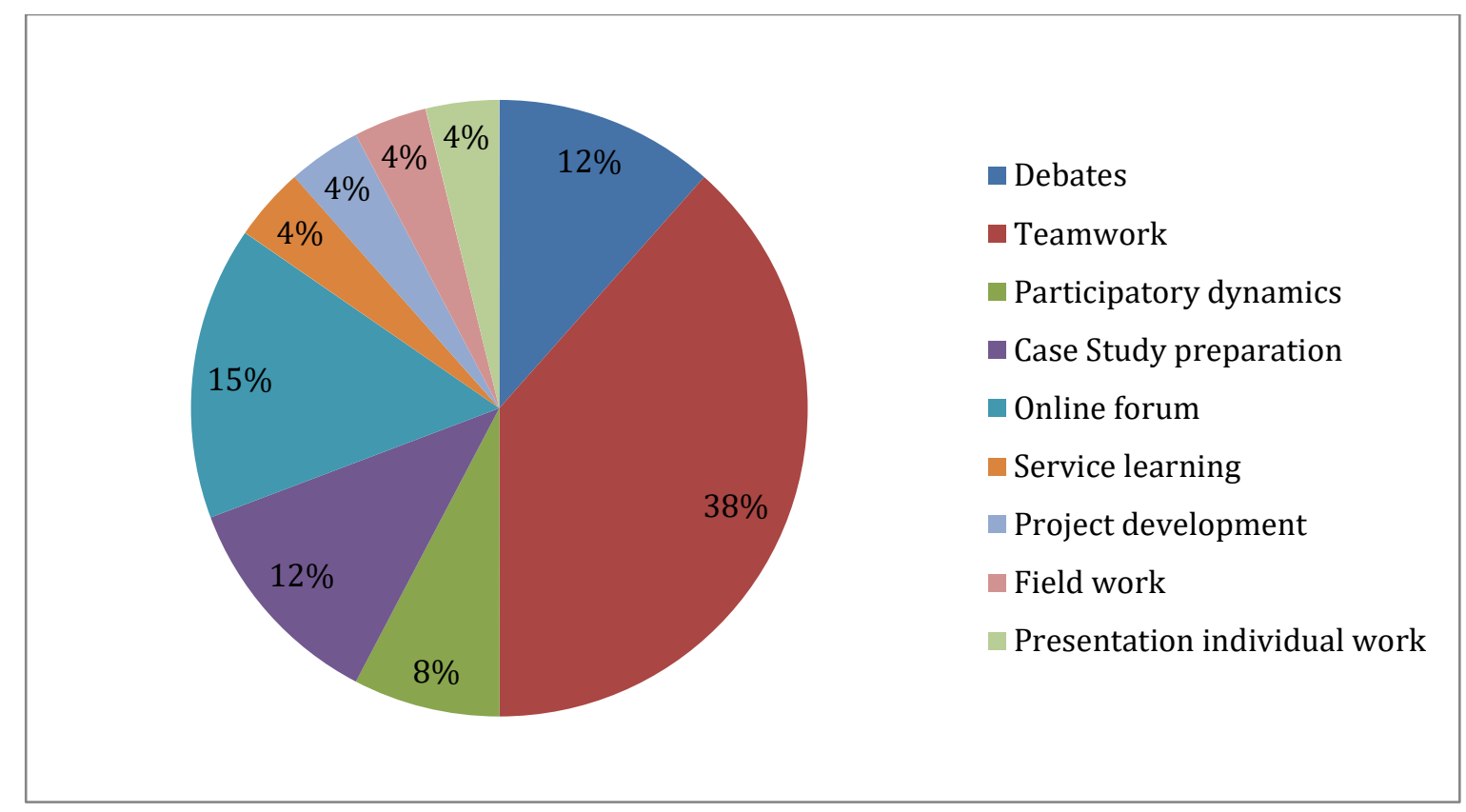

Figure 3. Active participation mechanisms

Figure 4 presents the evaluation and grading mechanisms selected by respondents. It can be noted that the 'final exam' is the factor which respondents gave most importance to, followed by 'teamwork' with a significant presence, and by 'independent work'. Peer evaluation was indicated as the least important factor considered when grading students. 


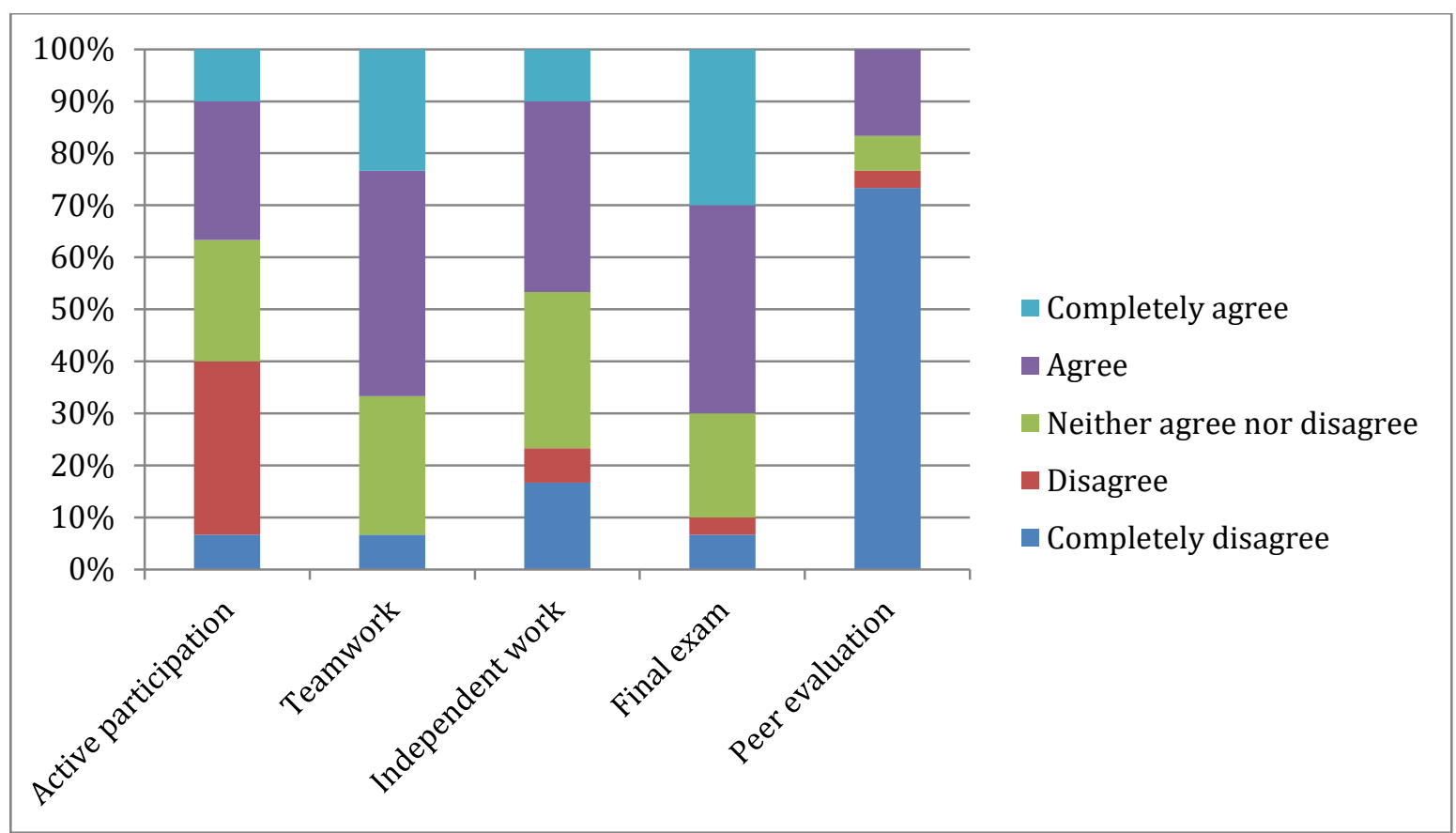

Figure 4. Evaluation and grading mechanisms

The great majority of the respondents (94\%) indicated that their respective universities have integrated transversal competences in their curricula. A total of $83 \%$ of these academics consider that these competences are related to GD. A thorough analysis of the websites of the universities where respondents are affiliated revealed that the great majority of these institutions have made efforts to increase their commitment to SD, specifically by including transversal competences in their teaching functions. The institutional promotion of the competences related to SD are formally focused on different concepts, which can be summarised as:

- Sustainability and social commitment

- Environmental and professional ethical responsibility

- Environmental and social responsibility

- Environmental awareness

- Knowledge of contemporary challenges

- Application of critical thinking

The institutions examined followed different strategies to implement transversal competences in teaching: proposing different levels of mastery of specific competences, placing the emphasis on specific concepts - sometimes not referring explicitly to SD - promoting the same transversal competences for all the courses offered or setting specific competences for particular courses, etc.

Overall, when related to environmental and social issues, the competences analysed generally aim to enhance the knowledge and comprehension of the main concepts related to SD, specifically from an approximation highlighting the complexity and interrelation of contemporary environmental, social and economic phenomena, particularly from the perspective of globalisation. Given that the decisions and actions of engineers and architects have a great impact on the environment and society, the message of the universities 
examined is that these categories should work for the public interest, following professional ethics and sustainability principles.

Those universities offering also bachelor's and master's degree programmes in geography also include transversal competences emphasising concepts such as:

- Sensitivity to ethnical and cultural diversity

- Acknowledgement of diversity and multiculturalism

- Promotion of human rights, democratic principles and gender equality

- Promotion of a culture of peace

More than half of the institutions examined offer resources through their webpage for those academics willing to expand these issues as well as courses addressed to academics. However, promoting these initiatives does not ensure that the respective institutions effectively implement transversal competences within their teaching systems.

A total of $83 \%$ of the respondents claimed that they personally integrate GD into their teaching activities through transversal competences and $67 \%$ and $61 \%$, respectively, consider that GD are also integrated in bachelor's/master's thesis and in other subjects of the courses of study. The survey asked academics to indicate public links detailing information on personal teaching activity, such as syllabuses, subject guides, etc. A detailed analysis of this public material has been used to detail the ways through which academics integrate SD issues into their teaching subjects. The authors took the work of Allen et al. (2008) as a reference for analysing the integration of sustainability concepts into engineering curricula in $\mathrm{HEI}$ in the United States. Following the proposal of the cited authors, the subjects indicated by respondents were divided into the four main approaches used to integrate SD in the curricula: i) integrating sustainable engineering concepts into traditional engineering courses, was the most represented category, accounting for 61\%; ii) courses focusing on technologies predicted to be important in developing sustainable engineering solutions, with $18 \%$; iii) dedicated sustainable engineering courses, with 11\%; and iv) interdisciplinary courses developed in collaboration with a non-engineering department, represented $11 \%$.

Overall, the respondents were involved in activities related to teaching innovation (Figure 5). It is noteworthy that a significant activity undertaken was that of promoters of courses of teaching innovation (50\%). A total of 39\% indicated that they were the author of publications or articles on this subject and only $22 \%$ participated in courses on teaching innovation. Among the most relevant issues specified as promoters, are noteworthy training activities relating SD (in its different variants as GD, SHD, Education for Development, Education for Sustainable Development) and engineering. Other issues indicated were: learning and service, urbanism, renewable energy and geographical information systems (GIS). 


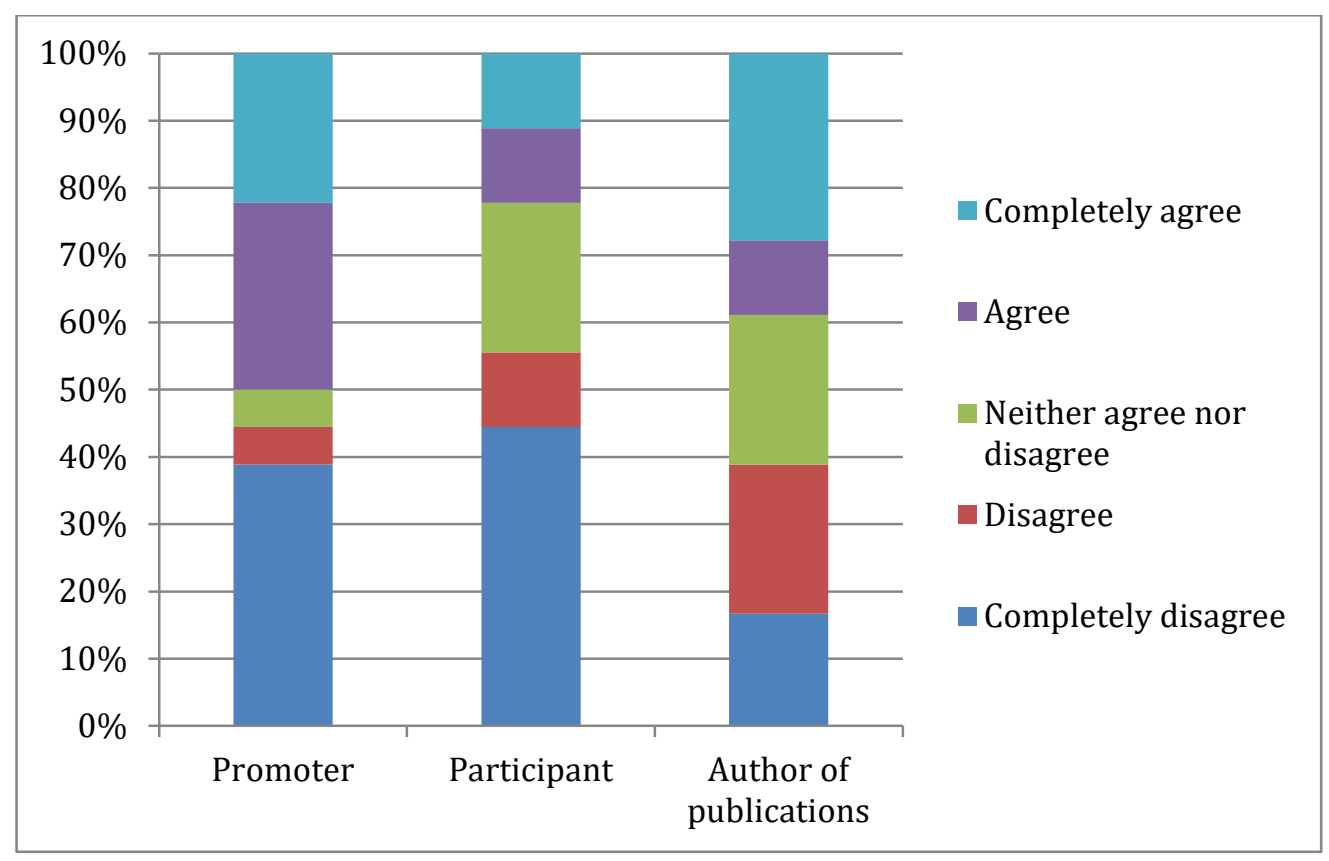

Figure 5. Engagement in teaching innovation activities

Focusing on teaching activity, it is worth emphasising that the results indicate that transversal competences adopted by universities are, for the great majority, related to the SD, namely: extreme poverty, human rights, globalisation, equality issues and environmental challenges. Furthermore, respondents state that global dimensions are integrated, through transversal competences, in different subjects of the courses of study, as well as through bachelor's/master's theses. On the one hand, this is coherent with research on the implementation of sustainability practices in the Spanish university system, whose findings indicate that sustainability practices related to students are those most commonly implemented (Larrán-Jorge et al., 2015). The findings of the present research confirm the presence of sustainability integration, specifically regarding engineering faculties. On the other hand, this contrasts with scientific literature focusing on engineering studies (Davidson et al., 2010; Lozano and Lozano, 2014) that substantially reports that incremental improvements focused on individual courses on SD are more common approaches than holistic curriculum reforms; specifically in engineering faculties (von Blottnitz et al., 2015). For this reason, it is essential to further explore the effective integration of SD in engineering courses.

\subsubsection{Research activities}

Respondents were asked to indicate up to three codes from the UNESCO nomenclature for the fields of science and technology on which they focus their research activity. In order to facilitate the interpretation of the data, the responses of the academics were grouped into the 'fields' of this nomenclature, namely: the top concepts of Science and Technology, encoded with the first two digits of the complete six-digit code. They specifically refer to the most general sections of the proposed nomenclature, which comprise several related disciplines and sub-disciplines. Table 3 shows the main fields of research indicated by the respondents; the full response, including the digits indicating disciplines and sub-disciplines, can be consulted in Annex A. 
In coherence with the profile of the respondents, Technological Sciences was the most represented field, accounting for $53 \%$. This field was followed by Sociology, with $10 \%$, then by Science of Arts and Letters and Economic Sciences, both representing 8\%. It is worth highlighting that sub-disciplines linked to Sociology were related to development studies and Urban Sociology; while those linked to Science of Arts and Letters were mainly related to Architecture and Urbanism.

Table 3. Foremost research fields of the respondents

\begin{tabular}{|c|l|c|c|}
\hline Code & \multicolumn{1}{|c|}{ UNESCO Fields } & Responses & $\%$ \\
\hline 12 & Mathematics & 1 & $2 \%$ \\
\hline 25 & Earth and Space Sciences & 3 & $6 \%$ \\
\hline 33 & Technological Sciences & 27 & $53 \%$ \\
\hline 53 & Economic Sciences & 4 & $8 \%$ \\
\hline 54 & Geography & 2 & $4 \%$ \\
\hline 58 & Pedagogy & 3 & $6 \%$ \\
\hline 59 & Political Science & 1 & $2 \%$ \\
\hline 62 & Science of Arts and Letters & 4 & $8 \%$ \\
\hline 63 & Sociology & 5 & $10 \%$ \\
\hline 71 & Philosophy & 1 & $2 \%$ \\
\hline
\end{tabular}

The relation between teaching and research activities can be described, overall, as positive. Referring to the subjects indicated in the survey, $68 \%$ of the respondents indicated that the subject they teach is strongly correlated with their research activities. Furthermore, 94\% consider that their teaching and research activities reciprocally feed into each other. This is confirmed in the related open-ended questions, where many academics describe that research conducted in the area of SD provides the basis on which most of their teaching activity is grounded. Specifically, case studies based on research outcomes are successfully used in class to complement theoretical issues. In fact, respondents highlighted that sharing the results of research initiatives with students provides the subjects they teach with more credibility, and is highly appreciated by students. It is also noted that teaching master's subjects adds an element of personal flexibility to professors by prioritising research topics that can easily be integrated into teaching practice.

The positive correlation between research and teaching expressed by the respondents is not consistent with the scientific literature that highlights, conversely, a lack of integration of these university functions as a barrier to further engage in efforts towards SD (Verhulst and Lambrechts, 2014). A deficit of integration is further confirmed by research conducted on Spanish universities that reports less practices aimed at fostering research on sustainability. Additionally, studies explicitly emphasise the insufficiency of interdisciplinary research groups capable of providing solutions according to the different perspectives of sustainability (Larrán-Jorge et al., 2015). This seems to reinforce the analysis of Ferrer-Balas et al. (2008) 
on the importance of interdisciplinary groups as connectors within and outside university boundaries.

\subsubsection{Sustainable Development Goals}

Figure 6 shows the degree of integration of SDGs into teaching activities. The SDGs that respondents integrated most into their teaching were 'Climate change adaptation' (SDG 13), followed by 'Conservation and sustainable use of ecosystems' (SDGs 14, 15) and, in third place, with the same value, 'Clean water and sanitation' (SDG 6) and 'Sustainable cities/communities and sustainable production and consumption patterns' (SDGs 11, 12). The SDGs with the lowest recognition were: 'Promotion of decent work and sustainable industrialisation' (SDGs 8 y 9), followed by 'Promotion of peace, justice and strong institutions' (SDG 16) and, in last position, 'Promotion of global partnership for SD' (SDG 17).

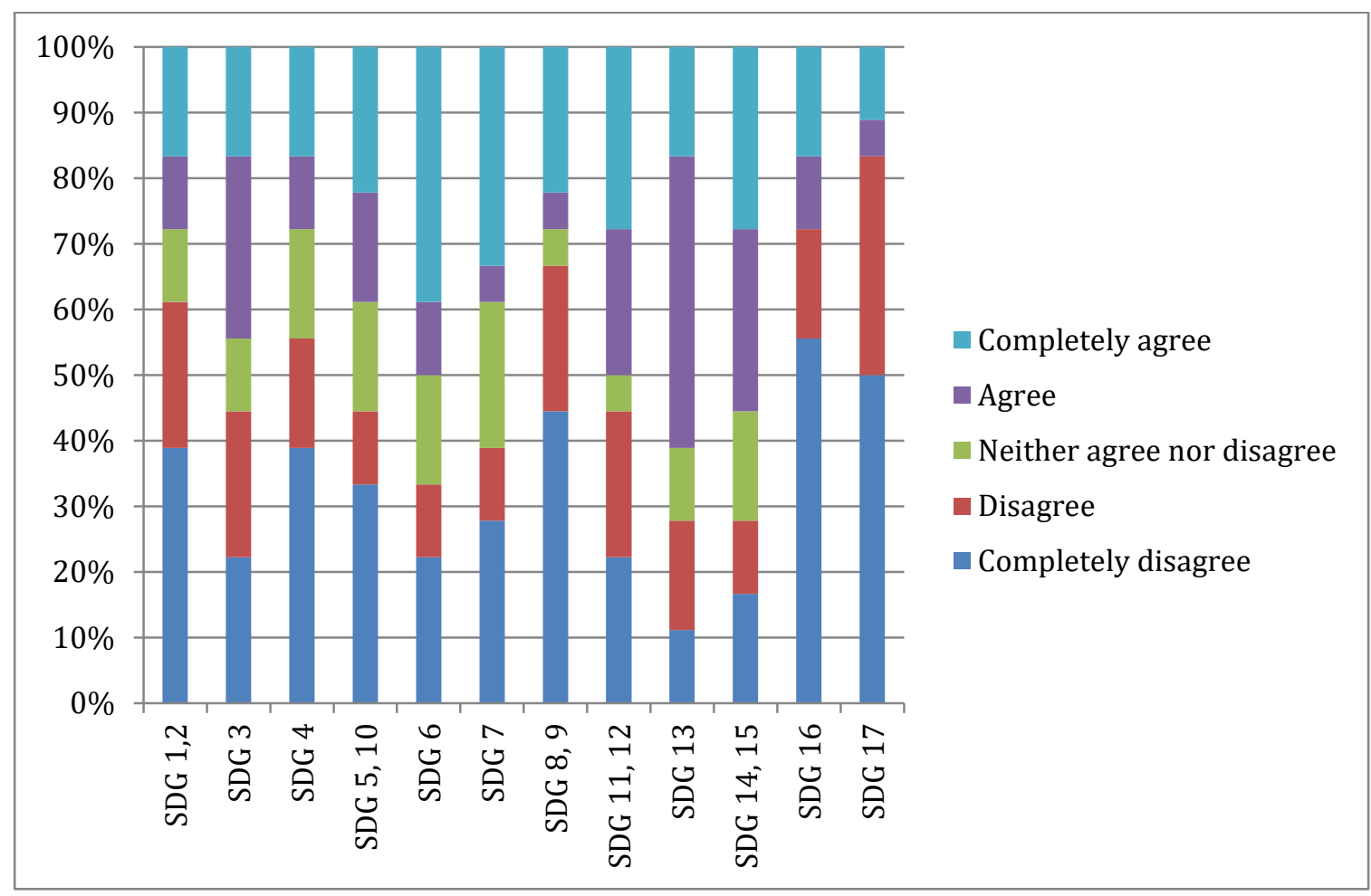

Figure 6. Integration of SDGs into teaching activities

Figure 7 shows the degree of integration of SDGs into research activities. The SDGs most acknowledged were 'Conservation and sustainable use of ecosystems' (SDGs 14, 15), followed by 'Clean water and sanitation' (SDG 6) and 'Sustainable cities/communities and sustainable production and consumption patterns' (SDGs 11, 12). The SDGs least integrated into research were: 'Promotion of global partnership for SD' (SDG 17), 'Affordable and clean energy' (SDG 7) and 'Promotion of peace, justice and strong institutions' (SDG 16), in the last position. 


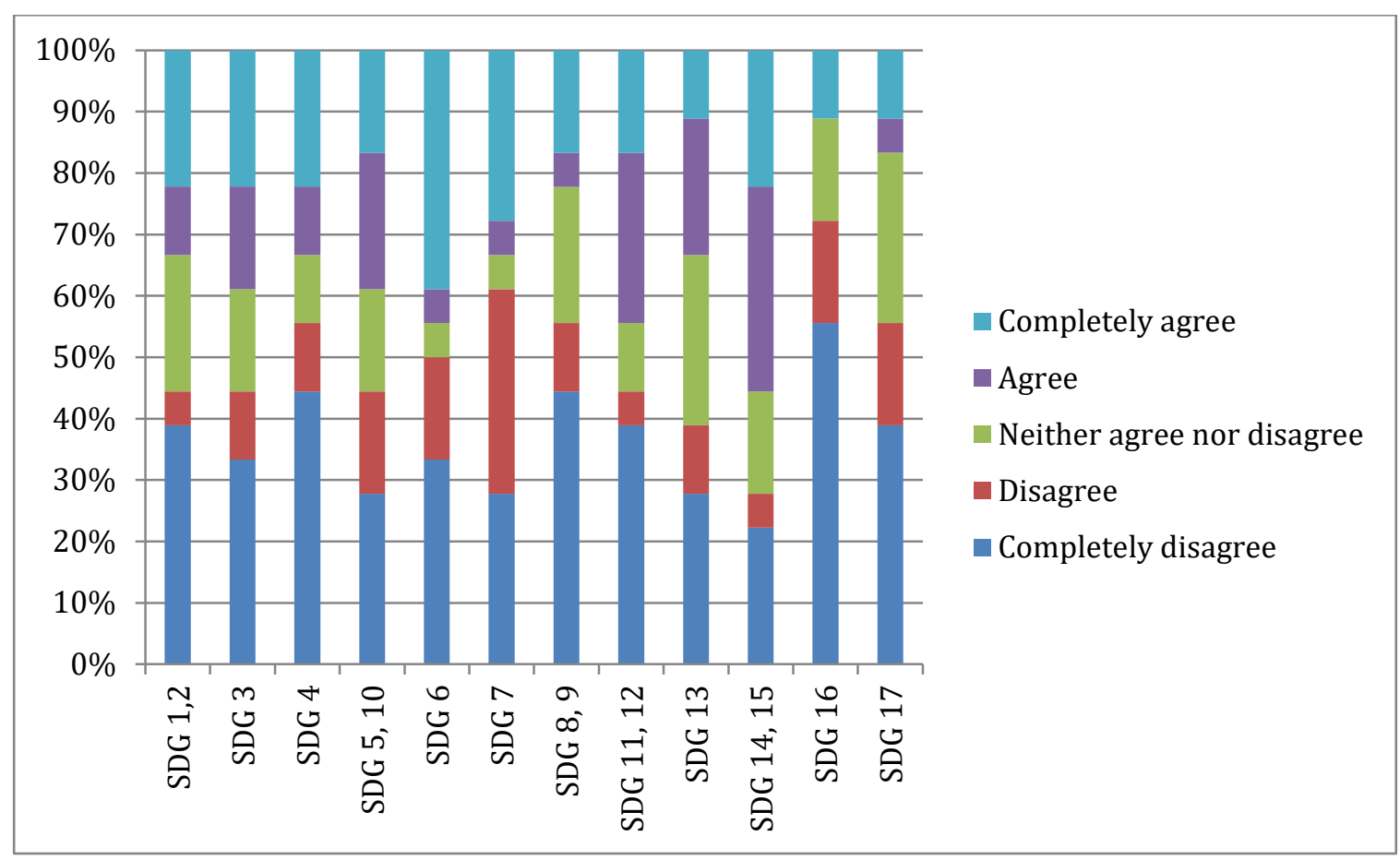

Figure 7. Integration of SDGs in research activities

A further question in this section was the perceived relation between SDGs and transversal competences implemented in respective universities. In this case, between $28 \%$ and $39 \%$ of the respondents opted not to provide information on the various items corresponding with SDGs. Presumably, a lack of significant knowledge of the various transversal competences conditioned the answers to this specific question. Those academics that chose to respond indicated 'Sustainable cities/communities and sustainable production and consumption patterns' (SDGS 11, 12) as the item with the highest relation between transversal competences and SDGs, followed by 'Affordable and clean Energy' (SDG 7) and 'Conservation and sustainable use of ecosystems' (SGDs 14, 15). The lowest relations were accorded to 'Promotion of peace, justice and strong institutions' (SDG 16) and 'Promotion of global partnership for SD' (SDG 17), respectively.

Results show that the degree of integration of SDGs, in both teaching and research endeavours, is mostly related to topics traditionally closer to scientific and engineering competences (such as climate change adaptation, conservation and the sustainable use of ecosystems, clean water and sanitation, sustainable production and consumption patterns) while, unsurprisingly, other relevant topics more related to social sciences and humanities, such as gender equality, poverty reduction and inclusive/equitable education, show lower levels of integration. This could be related to the separation of disciplines and the lack of the ability to work across different fields (Lozano et al., 2013) - recognised as major challenges of engineering curricula reform (Crofton, 2000; Halbe et al., 2015). Nonetheless, bibliometric analysis shows that academics of the GDEE group present a substantial degree of interdisciplinarity in scientific publications.

\subsubsection{Social Outreach}


Respondents were asked to indicate with which type of entities they usually engage outside the university with the aim of disseminating their academic activities and the kind of relationship they have with such entities. Figure 8 presents the respondents' engagement with different societal entities. The entities with the highest frequency were, respectively: public entities, Civil society organisations (CSOs), NGOs and International Development NGOs. Social and Environmental third sector were the entities with the lowest frequency. Figure 9 shows the specific relationship that participants have with each of the entities stated. It is interesting to note that respondents engage with public entities because of the existence of a project with financial allocation or due to institutional relationship. Conversely, their engagement with CSOs/NGOs and International Development NGOs was mostly due to their own initiative. Student practice activities were mostly concentrated in domestic firms and SMEs.

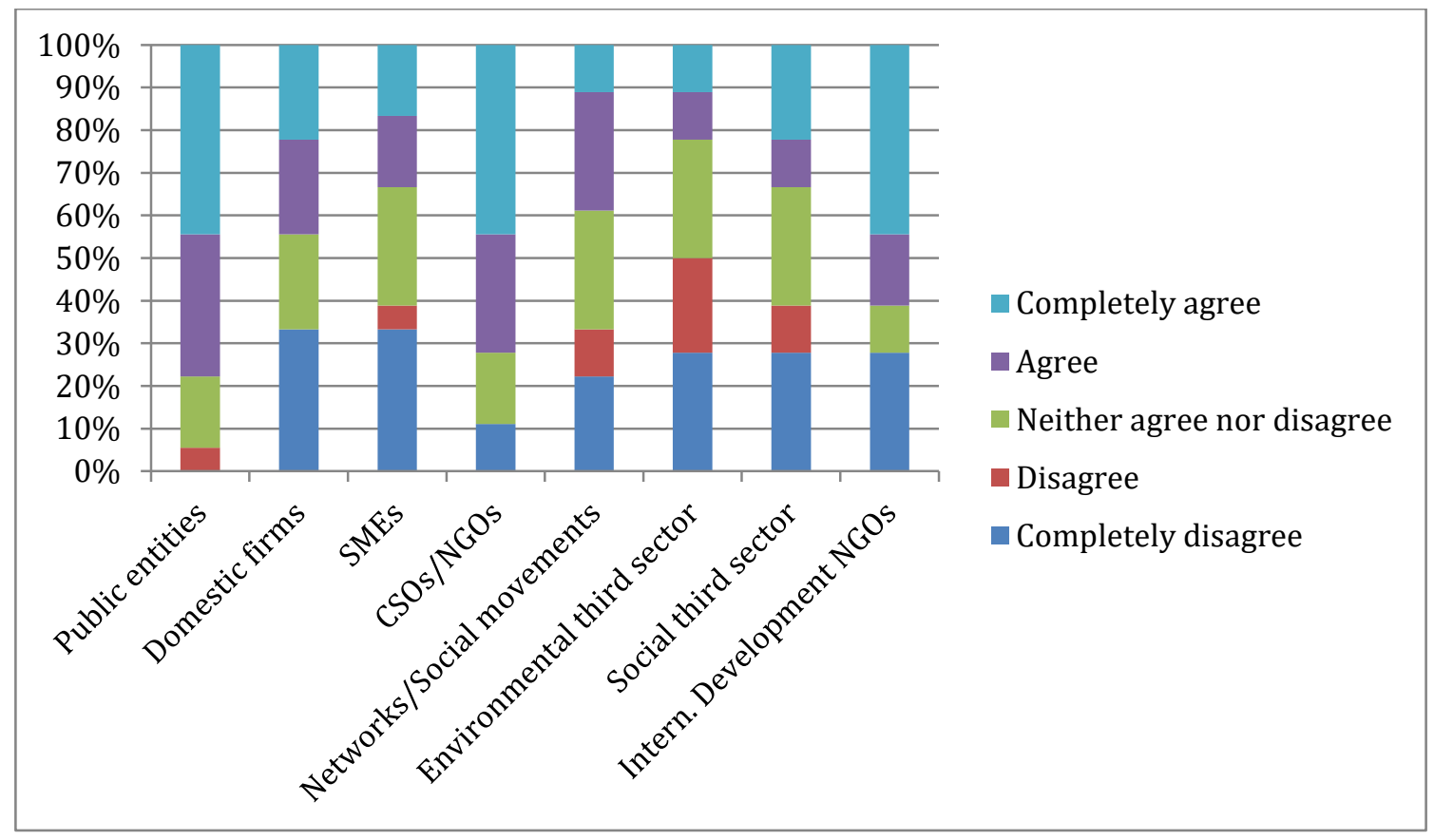

Figure 8. Respondents' engagement with societal entities. 


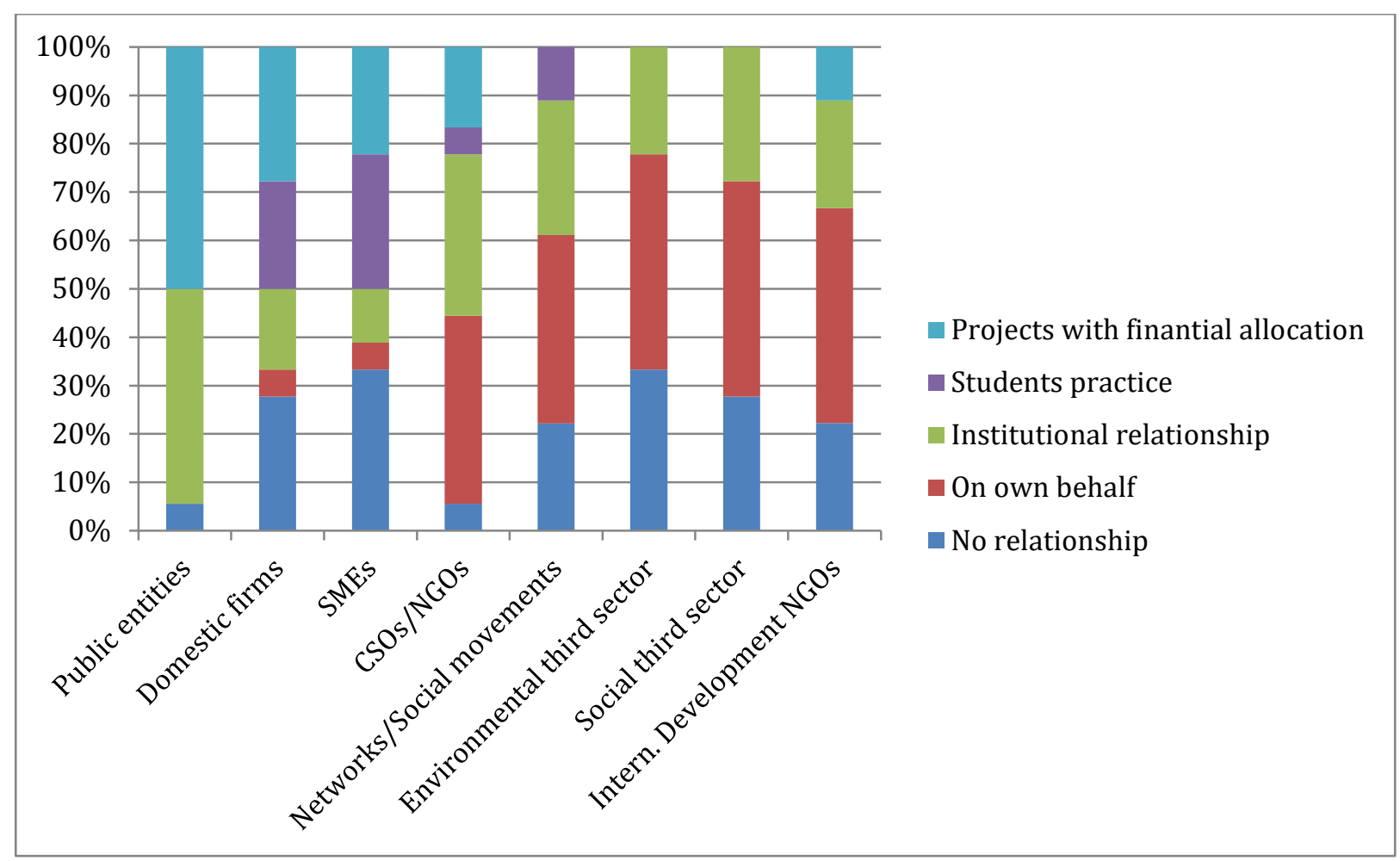

Figure 9. Respondents' relationship with social entities

Regarding the dissemination of research outcomes, respondents prioritised first quartile scientific journals, followed by international conferences and journals of all databases, as shown in Figure 10. Dissemination addressed to a non-scientific audience, such as popular articles, blogs or press were the items with least relevance.

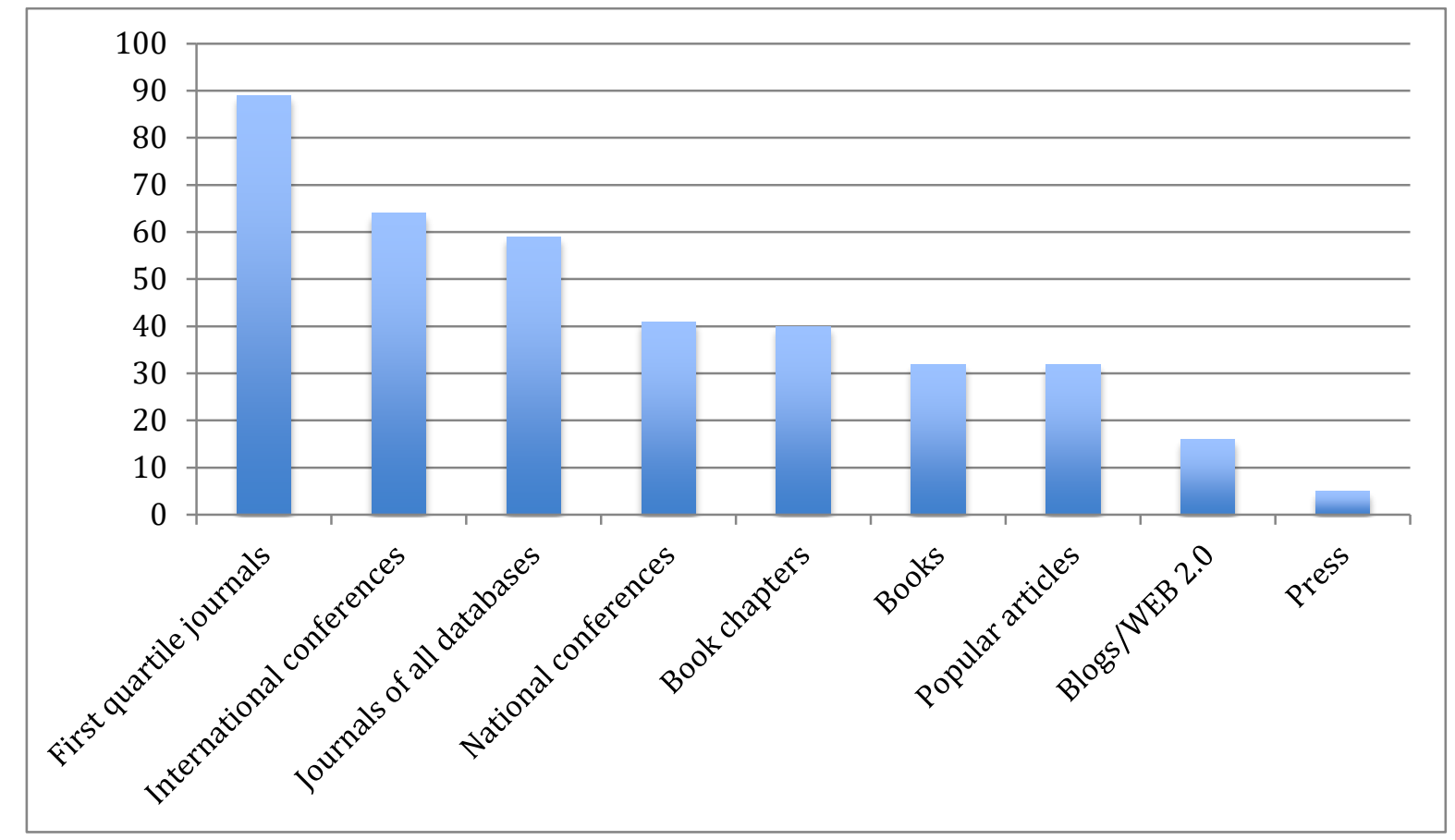

Figure 10. Dissemination of research outcomes prioritised by respondents. 
It is noteworthy to mention a lack of consensus on the definition of social outreach of universities and thus also on potential metrics for tracking and measuring the effectiveness of universities' outreach programmes. Generally, social outreach is not included as a rewarded activity of academics. In this research, the analysis of social outreach portrays academics as primarily being engaged with public entities due to funded projects and institutional relationship. Conversely, their engagement with social entities such as CSOs/NGOs is mostly on a personal level. Furthermore, the efforts aimed at disseminating scientific outcomes are mostly concentrated on scientific contexts, while popular dissemination is quite insignificant. This description is consistent with other analyses on the role of academics in the contemporary university, which describe an increasingly "corporate approach" in HEI (Morrissey, 2013) where professional results are emphasised over public service and academics spend an increasing amount of time on managing activities and administrative requirements and less time is dedicated to connecting with the wider society (White, 2015). Furthermore, these results underpin the critics of different agents of the social sector, such as CSOs/NGOs, stating that university has been unable to enhance collaboration channels with social entities (Zolezzi et al., 2013).

\subsubsection{Perception of the recognition/evaluation of academics merits}

Respondents were asked to select, in a multiple-choice question, all relevant items of the university monitoring of academic activity of professors. Research, with $90 \%$ of responses, was the most relevant issue of the monitoring function that universities perform on academic activities, followed by teaching (83\%) and knowledge transfer activities (78\%). Social Outreach, unsurprisingly, was not indicated as an aspect monitored by universities.

University evaluation mechanisms were not particularly well appraised by respondents. Despite the fact that the Likert scale provides a central value (neither agree nor disagree), a high percentage of the respondents (33\%) gave a negative assessment of the evaluation system.

Open-ended questions highlighted both positive and negative factors related to the academic evaluation system. Among the former, respondents highlighted the possibility to have access to resources managed by universities, for example resources that the university dedicates to finance specific projects for research or doctoral scholarships. Another positive issue highlighted was the reduction of the teaching load of academics involved in successful research initiatives. The most critical views indicated that the majority of activities carried out by academics are usually not taken into account in the recognition of academic merits, and that research merits often are not considered for the reallocation of the teaching load among other colleagues.

According to the answers, more than $80 \%$ of the respondents have been evaluated by quality accreditation agencies. The majority of them negatively assessed the process of accreditation of academics, indicating various reasons. Firstly, they emphasised that the procedures for accreditation involve burdensome bureaucratic requirements, which are often not entirely transparent. Secondly, some of them criticised the concept of academic quality accepted and applied in accreditation processes, especially stressing the ambiguity of criteria and scales that may lead to considerable disparities between colleagues. Finally, younger academics highlighted different accreditation requirements between senior and junior academics. In fact, in recent decades, Spanish accreditation requirements have been 
tightened and more demanding requirements, such as leading a European project as Principal Investigator, now concern younger academics.

It is worth emphasising the critical view that the majority of the academics expressed on the evaluation system, for both universities and accreditation agencies. This perception is consistent with research conducted in Spanish universities highlighting that incentives to improve the teaching and research activities of academics are not perceived as adequate (Caballero Rodríguez, 2013). Research is the most relevant item monitored by universities and accreditation agencies, and social outreach was not indicated as a monitored item. This reinforces previous studies suggesting that universities are increasingly focusing on research to evaluate academic merits (Hazelkorn, 2014; Locke, 2014) and that HEI do not foster social outreach (Stephens et al., 2008). Furthermore, the literature indicates that accreditation agencies can play a great role in advancing sustainability in engineering education (Rose et al., 2015). Unfortunately, this role is not always clearly recognised by accreditation agencies.

\subsection{Analysis of scientific production}

An analysis of scientific publications for each of the 18 academics completing the survey was performed, using the Scopus database. Data were gathered and grouped in order to be processed with the application Overlay.exe.

Findings of the bibliometric analysis can be easily visualised in Figure 11, with the help of overlaid Science Maps. The figure shows the journal distribution of the scientific production of the 18 academics answering the survey, according to Scopus classification, highlighted onto a base map of global science (in pale green). Clearly visible at the top of the two maps, in blue and yellow, are the journals of fields related to engineering disciplines, which are predominant subjects of research of the academics analysed, coherent with the target of the GDEE initiative, as well as journals of Environmental Science, shown in green. Thus, the journal distribution shows a spread in opposing research areas, respectively left for categories related to social science journals and right for categories related to medicine and engineering, such as biotechnology, biomaterials, biophysics, etc.

The degree of the spread of publications onto the base map of global science, and the interdisciplinarity of the researchers involved in the analysis, can be better discerned by comparing the GDEE group with other groups analysed with the same method. 


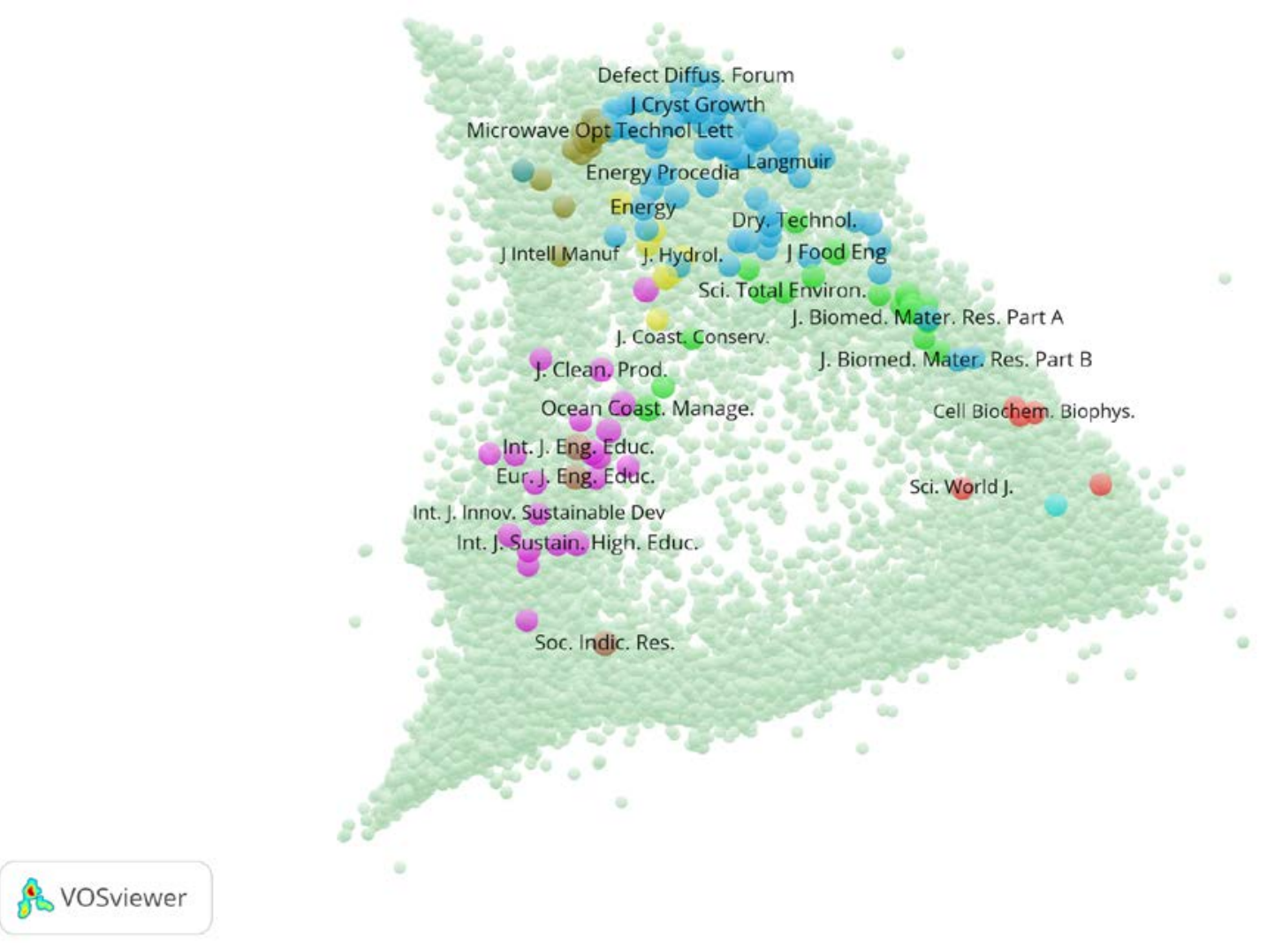

Figure 11. Journal distribution of GDEE academics.

As an example, Figure 12 shows Scopus-based overlay maps, presented in the framework of a study conducted by Leydesdorff et al. (2015) comparing journal publication portfolios between the Science and Technology Policy Research Unit (SPRU) at the University of Sussex (on the left) and the London Business School (on the right). The interdisciplinarity of different portfolios of publications can be visually assessed with this tool.
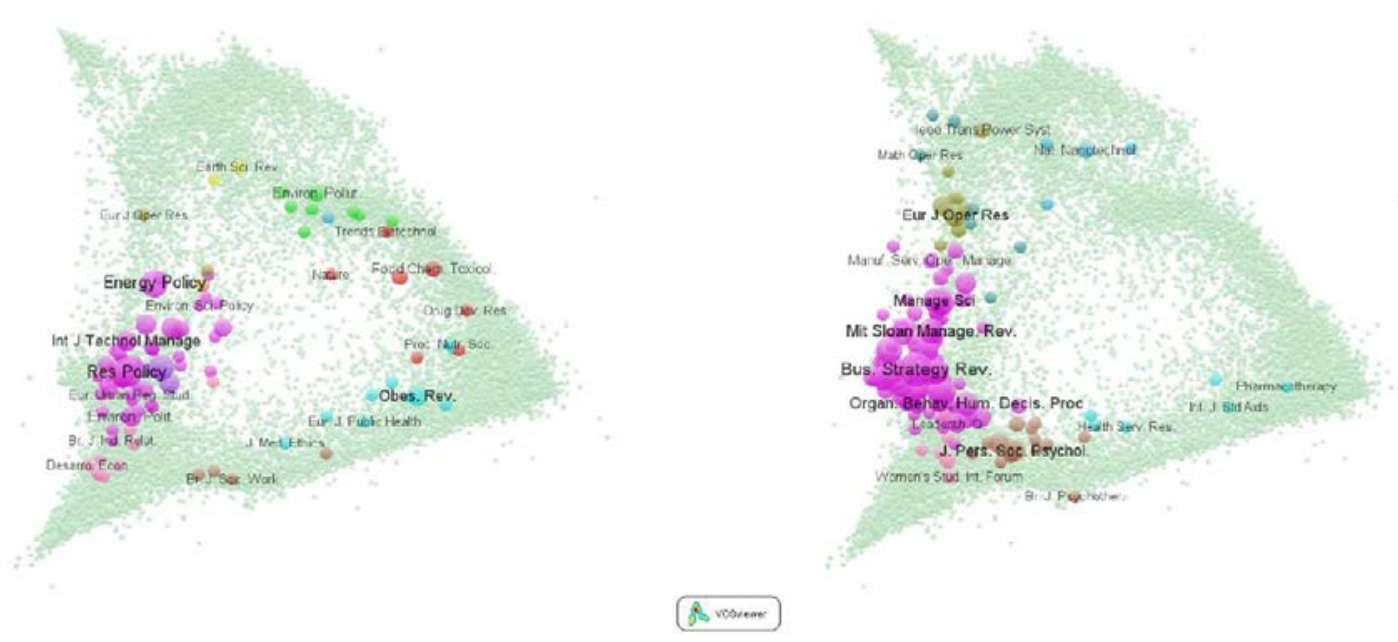

Figure 12. Scopus-based overlay maps comparing journal publication portfolios between the Science and Technology Policy Research Unit SPRU at the University of Sussex (left) and the London Business School (right). Source: Leydesdorff et al. (2015). 
Furthermore, the Rao-Sterling interdisciplinary index can be operationalised by integrating the values of the distance between the respective subsets of journals provided by the map. The calculation of the Rao-Sterling index confirms that the degree of interdisciplinarity of the GDEE group is higher than the other two portfolios. Specifically, the Rao-Stirling diversity index is: 0.1713 for the GDEE group analysed while for the SPRU Unit and the London Business School the values are 0.149 and 0.091, respectively, as reported by Leydesdorff et al. (2015).

The bibliometric analysis of the scientific publications of academics completing the survey highlights relevant issues. The members of the group analysed are involved in research activity in different disciplines of the map of science. It is relevant to note that there is an intense research activity not only in engineering related disciplines, but also in social sciences. In addition, participants are particularly active in disciplines related to medicine and engineering. It can be argued that academics, including those with an established research career and a high degree of interdisciplinary research, are looking for a wider perspective and understanding of global challenges relevant to SD, and their relations with the field of engineering. Furthermore, the GDEE profiles can be seen, at least from the research perspective, as potential connectors with diverse disciplines, in line with the analysis of Ferrer-Balas et al. (2008).

\section{Conclusions}

Engineering covers essential aspects related to SD and it is vital that professional engineers be able to respond adequately and urgently to global challenges. Polytechnic universities and engineering faculties have made major progress in this direction. Nevertheless, more efforts are needed in order to advance and make deep transformations and enable an organic integration of SD into all university functions. The practical and structured orientation of engineering education and methods, make the promotion of a cultural shift towards frameworks of knowledge defined by uncertainty, complexity and cultural sensitivity particularly challenging.

This work is specifically addressed at enhancing the understanding of the academic profile of academics engaged in training activities related to SD, and provides an analysis based on different methods: a semi-structured survey and a bibliometric analysis using maps of science. The results indicate that academics involved in SD practices, in the framework of GDEE training activities, are academics whose teaching and research activities range from engineering to social science, as well as fields related to medicine and engineering, and the great majority are involved in activities with societal entities and movements. Thus, they may be described as potential 'connectors' with other research groups at universities as well as with the wider society. It can be argued that they are promoters of those educational principles and values related to SD - such as inter- and transdisciplinarity, integrating the social dimension in technical-related approaches to SD - that can facilitate a cultural change in engineering education, and lead to more holistic transformations.

A critical aspect emphasised by the results is related to the role of academics as agents of change. This research confirms that academics are not sufficiently engaged, through their activities, in facilitating a transition of societal setting toward SD. 
Universities are expected to function as leaders of societal change towards SD. Our results reveal that sustainability champions do not feel sufficiently supported in their activities and that their efforts mostly go unrewarded. Furthermore, participants consider that accreditation procedures are not entirely transparent and potentially lead to disparities between colleagues. The role and commitment of accreditation agencies and professional accreditation bodies can be extremely positive in advancing SD, especially for engineering education. HEl committed with SD should advocate for a reform of competency requirement of engineering that integrates SD principles, as well as accreditation procedures that recognise social outreach activities.

In any case, universities should devote more efforts towards exploring internal mechanisms to promote the engagement of academics in SD. Firstly, because each university can better calibrate incentives, assessing specific situations and personal efforts within particular academic functions. Secondly, because complex bureaucratic procedures are reflected in substantial time lags in the reform of accreditation systems.

The authors of this research suggest various recommendations addressed to higher education leaders in the faculty of Engineering.

First, engage sustainability champions and potential 'connectors' (within the university system and outside university boundaries) in all efforts aimed at implementing SD throughout the university system, including staff development programmes.

Second, integrate policies and mechanisms to recognise the work of academics engaged in SD. Specifically, give academic merit to all those activities and initiatives aimed at promoting, in non-academic contexts, a deeper understanding of SD global challenges, as well as all contributions aimed at enhancing liaisons outside academia focused on SD.

Third, advocate at regional and national level for a reform of competency requirement of engineering that integrates SD principles. 


\section{Acknowledgments}

The authors would like to thank $\mathrm{Dr}$ Ismael Ràfols, Ingenio CSIC-UPV, and Dr Loet Leydesdorff, University of Amsterdam, for their valuable support on journal maps and interactive overlays used in this article. They would also thank the respondents of the survey for their participation.

The research was conducted in the framework of the European initiative 'Global Dimension in Engineering Education', financed by:

- European Commission, Non-State Actors and Local Authorities in Development: Raising public awareness of development issues and promoting development education in the European Union. Reference: EuropeAid/131141/C/ACT/MULTI, Number of proposal: DCINSAED/2011/63

- Barcelona City Council, Programme: Barcelona Solidaria 2013. Grant number: 13ED0046

Funding sources had no involvement in the design of the study; in the collection, analysis and interpretation of data; in the writing of the report; nor in the decision to submit the article for publication. 


\section{Annex A}

Responses to the survey question: 'With regard to your research activity, could you please indicate up to three codes of UNESCO's international nomenclature?

\begin{tabular}{|c|c|c|}
\hline Code & Description & Resp. \\
\hline 120600 & Numerical Analysis & 1 \\
\hline 250604 & Environmental geology & 1 \\
\hline 250810 & Precipitation & 1 \\
\hline 250814 & Surface waters & 1 \\
\hline 330300 & Chemical technology and Engineering & 1 \\
\hline 330303 & Chemical Processes & 1 \\
\hline 330306 & Combustion technology & 1 \\
\hline 330500 & Construction technology & 1 \\
\hline 330530 & Sewers and water purification & 1 \\
\hline 330701 & Antennae & 1 \\
\hline 330709 & Photo-electric devices & 1 \\
\hline 330714 & Semi-conductor devices & 1 \\
\hline 330800 & Environmental technology & 1 \\
\hline 330809 & Sanitary engineering & 1 \\
\hline 330810 & Sewage technology & 2 \\
\hline 330890 & Food technology & 1 \\
\hline 330914 & Food processing & 1 \\
\hline 331210 & Plastics & 1 \\
\hline 331212 & Testing of materials & 1 \\
\hline 331499 & Medical technology Other & 1 \\
\hline 332202 & Power Generation & 3 \\
\hline 332205 & Unconventional sources of energy & 2 \\
\hline 332505 & Radio communications & 1 \\
\hline 332818 & Mass transfer & 1 \\
\hline 332905 & Regional Development & 1 \\
\hline 332908 & Urban Environment & 1 \\
\hline 339900 & Other technological specialities & 1 \\
\hline 530407 & Production & 1 \\
\hline 531003 & International aid & 1 \\
\hline 531104 & Manpower management & 1 \\
\hline 531107 & Operations research & 1 \\
\hline 540300 & Human geography & 1 \\
\hline 540306 & Social geography & 1 \\
\hline 580103 & Curriculum development & 1 \\
\hline 580107 & Pedagogical Methods & 1 \\
\hline 580199 & Educational theory and methods Others & 1 \\
\hline 590101 & International co-operation & 1 \\
\hline 620101 & Architectural Design & 1 \\
\hline 620103 & Urbanism & 2 \\
\hline 620308 & Photography & 1 \\
\hline 630700 & Social change and development & 1 \\
\hline
\end{tabular}


630702 Developing countries

631008 Poverty

1

631106 Urban sociology

2

710304 Ethics of science 


\section{References}

Absell, C.D., 2015. The Lexicon of Development: A Quantitative History of the Language of Development Studies. Iberoam. J. Dev. Stud. 4, 4-34.

Allen, D., Allenby, B., Bridges, M., Crittenden, J., Davidson, C., Hendrickson, C., Matthews, S., Murphy, C., Pijawka, D., 2008. Benchmarking Sustainable Engineering Education. University of Texas at Austin, Carnegie Mellon University, Arizona State University.

Barth, M., Rieckmann, M., 2012. Academic staff development as a catalyst for curriculum change towards education for sustainable development: An output perspective. J. Clean. Prod. 26, 28-36. doi:10.1016/j.jclepro.2011.12.011

Boni, A., Pérez-Foguet, A., 2008. Introducing development education in technical universities: successful experiences in Spain. Eur. J. Eng. Educ. 33, 343-354. doi:10.1080/03043790802088723

Byrne, E.P., Desha, C.J., Fitzpatrick, J.J., Hargroves, K., 2013. Exploring sustainability themes in engineering accreditation and curricula. Int. J. Sustain. High. Educ. 14, 384403. doi:10.1108/IJSHE-01-2012-0003

Caballero Rodríguez, K., 2013. Academics' satisfaction level towards evaluation systems. Rev. Educ. 360, 483-508. doi:10.4438/1988-592X-RE-2011-360-124

Cebrián, G., Grace, M., Humphris, D., 2015. Academic staff engagement in education for sustainable development. J. Clean. Prod. 106, 1-16. doi:10.1016/j.jclepro.2014.12.010

Chadegani, A.A., Salehi, H., Yunus, M.M., Farhadi, H., Fooladi, M., Farhadi, M., Ebrahim, N.A., Aghaei Chadegani, A., Salehi, H., Md Yunus, M.M., Farhadi, H., Fooladi, M., Farhadi, M., Ale Ebrahim, N., 2013. A comparison between two main academic literature collections: Web of science and scopus databases. Asian Soc. Sci. 9, 18-26. doi:10.5539/ass.v9n5p18

Clark, W.C., Dickson, N.M., 2003. Sustainability science: the emerging research program. Proc. Natl. Acad. Sci. U. S. A. 100, 8059-8061. doi:10.1073/pnas.1231333100

Crofton, F.S., 2000. Educating for sustainability: Opportunities in undergraduate engineering. J. Clean. Prod. 8, 397-405. doi:10.1016/S0959-6526(00)00043-3

Davidson, C.I., Hendrickson, C.T., Matthews, H.S., Bridges, M.W., Allen, D.T., Murphy, C.F., Allenby, B.R., Crittenden, J.C., Austin, S., 2010. Preparing future engineers for challenges of the 21st century: Sustainable engineering. J. Clean. Prod. 18, 698-701. doi:10.1016/j.jclepro.2009.12.021

Egelund Holgaard, J., Hadgraft, R., Kolmos, A., Guerra, A., 2016. Strategies for education for sustainable development - Danish and Australian perspectives. J. Clean. Prod. 112, 3479-3491. doi:10.1016/j.jclepro.2015.09.063

Fenner, R.A., Ainger, C.M., Cruickshank, H.J., Guthrie, P.M., 2005. Embedding sustainable development at Cambridge University Engineering Department. Int. J. Sustain. High. Educ. 6, 229-241. doi:10.1108/14676370510607205

Ferrer-Balas, D., Adachi, J., Banas, S., Davidson, C.I., Hoshikoshi, A., Mishra, A., Motodoa, Y., Onga, M., Ostwald, M., 2008. An international comparative analysis of sustainability transformation across seven universities. Int. J. Sustain. High. Educ. 9, 295-316. doi:10.1108/14676370810885907

Ferrer-Balas, D., Lozano, R., Huisingh, D., Buckland, H., Ysern, P., Zilahy, G., 2010. Going beyond the rhetoric: system-wide changes in universities for sustainable societies. J. Clean. Prod. 18, 607-610. doi:10.1016/j.jclepro.2009.12.009

Foxcroft, C., Paterson, H., Le Roux, N., Herbst, D., 2004. Psychological assessment in South 
Africa: A needs analysis. HSRC Library.

Gaziulusoy, A.I., Boyle, C., 2013. Proposing a heuristic reflective tool for reviewing literature in transdisciplinary research for sustainability. J. Clean. Prod. 48, 139-147. doi:10.1016/j.jclepro.2012.04.013

GDEE, 2015. Case studies for developing globally responsible engineers [WWW Document]. URL http://upcommons.upc.edu/handle/2117/88905

GDEE (Ed.), 2014. Global Dimension in Engineering Education [WWW Document]. URL http://upcommons.upc.edu/handle/2117/26502

Halbe, J., Adamowski, J., Pahl-Wostl, C., 2015. The role of paradigms in engineering practice and education for sustainable development. J. Clean. Prod. 106, 272-282. doi:10.1016/j.jclepro.2015.01.093

Hazelkorn, E., 2014. Reflections on a Decade of Global Rankings: What we've learned and outstanding issues. Eur. J. Educ. 49, 12-28. doi:10.1111/ejed.12059

Hoover, E., Harder, M.K., 2014. What lies beneath the surface? The hidden complexities of organizational change for sustainability in higher education. J. Clean. Prod. 106, 175188. doi:10.1016/j.jclepro.2014.01.081

Hugé, J., Mac-Lean, C., Vargas, L., 2018. Maturation of sustainability in engineering faculties - From emerging issue to strategy? J. Clean. Prod. 172, 4277-4285. doi:10.1016/j.jclepro.2017.07.143

Kajikawa, Y., Ohno, J., Takeda, Y., Matsushima, K., Komiyama, H., 2007. Creating an academic landscape of sustainability science: an analysis of the citation network. Sustain. Sci. 2, 221-231. doi:10.1007/s11625-007-0027-8

Krizek, K.J., Newport, D., White, J., Townsend, A.R., 2012. Higher education's sustainability imperative: how to practically respond? Int. J. Sustain. High. Educ. 13, 19-33. doi:10.1108/14676371211190281

Krogh Hansen, K., Dahms, M.L., Otrel-Cass, K., Guerra, A., 2014. Problem Based Learning and Sustainability: Practice and Potential. Faculty of Engineering and Science, Aalborg University.

Lang, D.J., Wiek, A., Bergmann, M., Stauffacher, M., Martens, P., Moll, P., Swilling, M., Thomas, C.J., 2012. Transdisciplinary research in sustainability science: practice, principles, and challenges. Sustain. Sci. 7, 25-43. doi:10.1007/s11625-011-0149-x

Larrán-Jorge, M., Herrera Madueño, J., Calzado Cejas, M.Y.M.Y., Andrades Peña, F.J., 2015. An approach to the implementation of sustainability practices in Spanish universities. J. Clean. Prod. 106, 34-44. doi:10.1016/j.jclepro.2014.07.035

Lazzarini, B., Pérez-Foguet, A., 2018. Profiling research of the engineering academics who successfully promote education in Sustainable Human Development. J. Clean. Prod. 172, 4239-4253. doi:10.1016/J.JCLEPRO.2017.08.234

Leal Filho, W., Nesbit, S. (Eds.), 2016. New Developments in Engineering Education for Sustainable Development. Springer. doi:10.1007/978-3-319-32933-8

Leydesdorff, L., de Moya-Anegón, F., Guerrero-Bote, V.P., 2015. Journal maps, interactive overlays, and the measurement of interdisciplinarity on the basis of Scopus data (19962012). J. Assoc. Inf. Sci. Technol. 66, 1001-1016. doi:10.1002/asi.23243

Leydesdorff, L., Rafols, I., 2011. Indicators of the interdisciplinarity of journals: Diversity, centrality, and citations. J. Informetr. 5, 87-100. doi:10.1016/j.joi.2010.09.002

Locke, W., 2014. The Intensification of Rankings Logic in an Increasingly Marketised Higher Education Environment. Eur. J. Educ. 49, 77-90. doi:10.1111/ejed.12060 
Lozano-García, F.J., Kevany, K., Huisingh, D., 2006. Sustainability in higher education: what is happening? J. Clean. Prod. 14, 757-760. doi:10.1016/j.jclepro.2005.12.006

Lozano, F.J., Lozano, R., 2014. Developing the curriculum for a new Bachelor's degree in Engineering for Sustainable Development. J. Clean. Prod. 64, 136-146.

doi:10.1016/j.jclepro.2013.08.022

Lozano, R., 2006. Incorporation and institutionalization of SD into universities: breaking through barriers to change. J. Clean. Prod. 14, 787-796.

doi:10.1016/j.jclepro.2005.12.010

Lozano, R., Ceulemans, K., Alonso-Almeida, M., Huisingh, D., Lozano, F.J., Waas, T., Lambrechts, W., Lukman, R., Hugé, J., 2015. A review of commitment and implementation of sustainable development in higher education: results from a worldwide survey. J. Clean. Prod. 108, 1-18. doi:10.1016/j.jclepro.2014.09.048

Lozano, R., Lozano, F.J., Mulder, K., Huisingh, D., Waas, T., 2013. Advancing Higher Education for Sustainable Development: International insights and critical reflections. J. Clean. Prod. 48, 3-9. doi:10.1016/j.jclepro.2013.03.034

Morrissey, J., 2013. Regimes of performance: practices of the normalised self in the neoliberal university. Br. J. Sociol. Educ. 36, 614-634. doi:10.1080/01425692.2013.838515

Mulder, K.F., Ferrer, D., Segalas Coral, J., Kordas, O., Nikiforovich, E., Pereverza, K., 2015. Motivating students and lecturers for education in sustainable development. Int. J. Sustain. High. Educ. 16, 385-401. doi:10.1108/IJSHE-03-2014-0033

Mulder, K.F., Segalàs, J., Ferrer-Balas, D., 2012. How to educate engineers for/in sustainable development Ten years of discussion, remaining challenges. Int. J. Sustain. High. Educ. 13, 211-218. doi:10.1108/14676371211242535

Pérez-Foguet, A., Lazzarini, B., Giné, R., Velo, E., Boni, A., Sierra-Castañer, M., Zolezzi, G., Trimingham, R., 2018. Promoting sustainable human development in engineering: Assessment of online courses within continuing professional development strategies. J. Clean. Prod. 172, 4286-4302. doi:https://doi.org/10.1016/j.jclepro.2017.06.244

Pérez-Foguet, A., Oliete-Josa, S., Saz-Carranza, A., 2005. Development education and engineering: A framework for incorporating reality of developing countries into engineering studies. Int. J. Sustain. High. Educ. 6, 278-303. doi:10.1108/14676370510607241

Porter, A.L., Cohen, A.S., David Roessner, J., Perreault, M., 2007. Measuring researcher interdisciplinarity. Scientometrics 72, 117-147. doi:10.1007/s11192-007-1700-5

Porter, A.L., Rafols, I., 2009. Is science becoming more interdisciplinary? Measuring and mapping six research fields over time. Scientometrics 81, 719-745. doi:10.1007/s11192-008-2197-2

Rose, G., Ryan, K., Desha, C., 2015. Implementing a holistic process for embedding sustainability: A case study in first year engineering, Monash University, Australia. J. Clean. Prod. 106, 229-238. doi:10.1016/j.jclepro.2015.02.066

Sammalisto, K., Sundström, A., Holm, T., 2015. Implementation of sustainability in universities as perceived by faculty and staff - a model from a Swedish university. J. Clean. Prod. 106, 45-54. doi:10.1016/j.jclepro.2014.10.015

Segalàs, J., Ferrer-Balas, D., Mulder, K.F., 2010. What do engineering students learn in sustainability courses? The effect of the pedagogical approach. J. Clean. Prod. 18, 275-284. doi:10.1016/j.jclepro.2009.09.012

Segalàs, J., Ferrer-Balas, D., Svanström, M., Lundqvist, U., Mulder, K.F., 2009. What has to be learnt for sustainability? A comparison of bachelor engineering education 
competences at three European universities. Sustain. Sci. 4, 17-27. doi:10.1007/s11625-009-0068-2

Stephens, J.C., Hernandez, M.E., Román, M., Graham, A.C., Scholz, R.W., 2008. Higher education as a change agent for sustainability in different cultures and contexts. Int. J. Sustain. High. Educ. 9, 317-338. doi:10.1108/14676370810885916

Trimingham, R., Lazzarini, B., Pérez-Foguet, A., Noble, N., Boni, A., Sierra-Castañer, M., Mongera, F., Zolezzi, G., 2016. Global Dimensions in Engineering Education: experiences from a collaborative project, in: Leal, W., Pace, P. (Eds.), Teaching Education for Sustainable Development at University Level. Springer, pp. 175-190. DOI: 10.1007/978-3-319-32928-4_12

UN Millennium Project, 2005. Investing In Development: A Practical Plan To Achieve The Millennium Development Goals. Washington, D.C.

UNESCO, 2014. Shaping the Future We Want. UN Decade of Education for Sustainable Development (2005-2014). Final Report. (Paris, France).

United Nations, 2015. Millennium Development Goals Report 2015, United Nations.

Velazquez, L., Munguia, N., Platt, A., Taddei, J., 2006. Sustainable university: what can be the matter? J. Clean. Prod. 14, 810-819. doi:10.1016/j.jclepro.2005.12.008

Verhulst, E., Lambrechts, W., 2014. Fostering the incorporation of sustainable development in higher education. Lessons learned from a change management perspective. J. Clean. Prod. 106, 189-204. doi:10.1016/j.jclepro.2014.09.049

von Blottnitz, H., Case, J.M., Fraser, D.M., 2015. Sustainable development at the core of undergraduate engineering curriculum reform: a new introductory course in chemical engineering. J. Clean. Prod. 106, 300-307. doi:10.1016/j.jclepro.2015.01.063

Wals, A.E.J., 2014. Sustainability in higher education in the context of the UN DESD: a review of learning and institutionalization processes. J. Clean. Prod. 62, 8-15. doi:10.1016/j.jclepro.2013.06.007

Watson, M.K., Lozano, R., Noyes, C., Rodgers, M., 2013. Assessing curricula contribution to sustainability more holistically: Experiences from the integration of curricula assessment and students' perceptions at the Georgia Institute of Technology. J. Clean. Prod. 61, 106-116. doi:10.1016/j.jclepro.2013.09.010

White, R.M., 2015. Who am I? The Role(s) of an Academic at a "Sustainable University," in: Leal Filho, W., Brandli, L., Kuznetsova, O., Paço, A.M.F. d. (Eds.), Integrative Approaches to Sustainable Development at University Level. Springer International Publishing, pp. 675-686. doi:10.1007/978-3-319-10690-8

Wiek, A., Withycombe, L., Redman, C.L., 2011. Key competencies in sustainability: A reference framework for academic program development. Sustain. Sci. 6, 203-218. doi:10.1007/s11625-011-0132-6

Withycombe Keeler, L., Wiek, A., Lang, D.J., Yokohari, M., van Breda, J., Olsson, L., Ness, B., Morato, J., Segalàs, J., Martens, P., Bojórquez-Tapia, L.A., Evans, J., 2016. Utilizing international networks for accelerating research and learning in transformational sustainability science. Sustain. Sci. 11, 749-762. doi:10.1007/s11625-016-0364-6

Wood, B.E., Cornforth, S., Beals, F., Taylor, M., Tallon, R., 2016. Sustainability champions? Academic identities and sustainability curricula in higher education. Int. J. Sustain. High. Educ. 17, 342-360. doi:10.1108/IJSHE-12-2014-0171

Zolezzi, G., Ortigara, A., Bezzi, M., Colombo, E., Mattarolo, L., Collivignarelli, C., Sorlini, S., Vaccari, M., Vitali, F., Mongera, F., Rizzi, I., Armando, G., Cancelliere, G., Fussi, F., 2013. Partnerships between academia and NGOs in technical studies in Italy, in: Imagining Cultures of Cooperation: Universities Networking to Face the New 
Development Challenges - Proceedings of the III CUCS Congress. Torino. 